\title{
Cannabinomics: Application of Metabolomics in Cannabis (Cannabis sativa L.) Research and Development
}

\author{
Konstantinos A. Aliferis ${ }^{1,2 *}$ and David Bernard-Perron ${ }^{3}$ \\ ${ }^{1}$ Laboratory of Pesticide Science, Agricultural University of Athens, Athens, Greece, ${ }^{2}$ Department of Plant Science, McGill \\ University, Montreal, QC, Canada, ${ }^{3}$ The Green Organic Dutchman, Mississauga, ON, Canada
}

\section{OPEN ACCESS}

Edited by:

Donald Lawrence Smith

McGill University, Canada

Reviewed by:

Hiroshi Noguchi,

Nihon Pharmaceutical University,

Japan

Derek Stewart,

The James Hutton Institute,

United Kingdom

${ }^{*}$ Correspondence:

Konstantinos A. Aliferis

konstantinos.aliferis@aua.gr;

konstantinos.aliferis@mcgill.ca

Specialty section:

This article was submitted to

Plant Metabolism

and Chemodiversity,

a section of the journal

Frontiers in Plant Science

Received: 05 December 2019

Accepted: 14 April 2020

Published: 08 May 2020

Citation:

Aliferis KA and Bernard-Perron D (2020) Cannabinomics: Application

of Metabolomics in Cannabis

(Cannabis sativa L.) Research and Development.

Front. Plant Sci. 11:554

doi: 10.3389/fp/s.2020.00554
Cannabis (Cannabis sativa L.) is a complex, polymorphic plant species, which produces a vast array of bioactive metabolites, the two major chemical groups being cannabinoids and terpenoids. Nonetheless, the psychoactive cannabinoid tetrahydrocannabinol $\left(\Delta^{9}\right.$. $\mathrm{THC}$ ) and the non-psychoactive cannabidiol (CBD), are the two major cannabinoids that have monopolized the research interest. Currently, more than 600 Cannabis varieties are commercially available, providing access to a multitude of potent extracts with complex compositions, whose genetics are largely inconclusive. Recently introduced legislation on Cannabis cultivation in many countries represents a great opportunity, but at the same time, a great challenge for Cannabis research and development (R\&D) toward applications in the pharmaceutical, food, cosmetics, and agrochemical industries. Based on its versatility and unique capabilities in the deconvolution of the metabolite composition of complex matrices, metabolomics represents an ideal bioanalytical tool that could greatly assist and accelerate Cannabis R\&D. Among others, Cannabis metabolomics or cannabinomics can be applied in the taxonomy of Cannabis varieties in chemovars, the research on the discovery and assessment of new Cannabisbased sources of bioactivity in medicine, the development of new food products, and the optimization of its cultivation, aiming for improvements in yield and potency. Although Cannabis research is still in its infancy, it is highly foreseen that the employment of advanced metabolomics will provide insights that could assist the sector to face the aforementioned challenges. Within this context, here, the current state-of-the-art and conceptual aspects of cannabinomics are presented.

Keywords: cannabinoids, cannabis terpenoids, chemovars, drug discovery, medicinal cannabis, plant metabolomics, plant chemotaxonomy

\section{INTRODUCTION}

Cannabis (Cannabis sativa L., Cannabaceae) (Figure 1) is a highly variable, complex, polymorphic plant species, which originates from Eurasia (Russo et al., 2008; Clarke and Merlin, 2013, 2016). Currently, it is distributed world-wide and grows in variable habitats, altitudes, and soil and climate conditions (Clarke and Merlin, 2016). There is a controversy among botanical taxonomists

Abbreviations: $\Delta^{9}$-THC, $\Delta^{9}$-tetrahydrocannabinol; CB1, CB2, cannabinoid receptors CB1, CB2; CBD, cannabidiol; GC/FID, gas chromatography-flame ionization detector platform; HRMS, high-resolution mass spectrometry; LC-DAD, liquid chromatography-diode array detector platform; MoA, mode(s)-of-action; NMR spectroscopy, nuclear magnetic resonance spectroscopy; PPPs, plant protection products; QC, quality control; R\&D, research and development. 
on the number of species that compose the Cannabis genus; presently, there is a consensus on the nomenclature proposed by Small and Cronquist (Small and Cronquist, 1976); C. sativa is monotypic, composed of two sub-species (subsp.), namely sativa and indica, based on their $\Delta^{9}$-tetrahydrocannabinol ( $\Delta^{9}$-THC) content. The former is further sub-divided into two varieties (var.), sativa (low $\Delta^{9}$-THC, domestication traits) and spontanea (low $\Delta^{9}$-THC, wild-type traits), and the latter into var. indica (high THC, domestication traits) and var. kafiristanica (high $\Delta^{9}$ THC, wild-type traits). Approximately 600 Cannabis varieties are commercially available (Rahn et al., 2016), whose genetics, for many of these, are only partially known. The plant has a diploid genome $(2 n=20)$ composed of nine autosomes and a pair of sex chromosomes ( $X$ and $Y$ ) (Ming et al., 2011) and its draft genome has recently been sequenced (Van Bakel et al., 2011).

The use and exploitation of Cannabis has sparked controversy, however, the recent legalization of its use for medical and other purposes in many countries within the corresponding legislative framework (Pacula and Smart, 2017; Cox, 2018), in combination with the remarkable bioactivities of the plant, pose an urge for the acceleration and intensification of Cannabis research and development (R\&D). Although it is still in its infancy, there is currently an exponentially increasing interest in Cannabis R\&D, as it is confirmed by the number of relative publications and citations (Figure 2).

Nevertheless, drug discovery, the risk assessment of cannabis products and their quality control (QC), and the research on the plant and its bioactive constituents, necessitate the implementation of advanced bioanalytical tools. Such tools could facilitate the acquisition of the necessary missing knowledge that will be further exploited toward the development of innovative, safe products, and the improvement of the plant's productivity in a timely fashion. Based on its versatility and unique capabilities in the deconvolution of the metabolite composition of complex matrices, metabolomics represents an ideal bioanalytical tool that could greatly accelerate Cannabis R\&D. Its successful implementation requires solid expertise in experimental design, analytical and bioanalytical chemistry, advanced statistics, and bioinformatics. To date, metabolomics has been developed for a wide range applications in various fields such as plant (Sumner et al., 2015) and food science (Wishart, 2008; Cevallos-Cevallos et al., 2009; Herrero et al., 2012; CastroPuyana and Herrero, 2013), medicine (Wishart, 2016), toxicology (Bonvallot et al., 2018; Viant et al., 2019), environmental sciences (Bundy et al., 2009), and plant protection products (PPPs) R\&D (Aliferis and Chrysayi-Tokousbalides, 2011; Aliferis and Jabaji, 2011). Nonetheless, since comprehensive reviews on the topics of metabolomics methodologies, analytical platforms, software, and cannabinoid analysis have been recently published (Madsen et al., 2010; Aliferis and Chrysayi-Tokousbalides, 2011; Fuhrer and Zamboni, 2015; Gromski et al., 2015; Markley et al., 2017; Leghissa et al., 2018b; Pellati et al., 2018; Ramirez et al., 2019; Atapattu and Johnson, 2020), these topics are not reviewed here.

For the application of metabolomics in Cannabis R\&D we are introducing the term "Cannabinomics" (Table 1). Its application could greatly assist the sector via the mapping of the metabolomes of the existing genotypes and their classification into the corresponding chemovars (Hazekamp et al., 2016; Lewis et al., 2018). Additionally, it has been predicted that the contribution of Cannabinomics toward the optimization and standardization of agricultural practices [e.g., application of plant growth regulators (PGR), bioelicitors, fertilizers, light conditions, irrigation events] for the production of superior quality products will be substantial (Magagnini et al., 2018). Similarly, it is expected to have a significant impact in the drug discovery, medicine, food science, functional cosmetics research, and metabolic engineering of microorganisms for the biosynthesis of cannabinoids. Here, the current state-of-the-art on these research topics, as well as conceptual aspects and perspectives, are being presented.

\section{CANNABIS (CANNABIS SATIVA L.): A UNIQUE FACTORY OF BIOACTIVE METABOLITES AND MULTI-COMPLEX MIXTURES}

The plant owes its reputation to the biosynthesis of a vast array of diverse metabolites that exhibit unique structures, physicochemical properties, and bioactivities; cannabinoids, which is a unique class of secondary plant metabolites (Figures 3, 5) and terpenoids (Figure 4), are the most important groups of Cannabis-derived metabolites. To date, approximately 600 Cannabis metabolites have been isolated, with more than $20 \%$ of them belonging to cannabinoids (Chandra et al., 2017). Among them, seven have been classified as CBD-type metabolites (Morales et al., 2017). In addition to the bioactive metabolites, the plant is a rich source of cellulosic and woody fibers (Andre et al., 2016). Therefore, the discovery and functional characterization of all the genes involved in the biosyntheses of cannabinoids is of paramount importance for the development of various applications, as discussed below. Nonetheless, the application of metabolomics in the field is still in its infancy.

The psychoactive metabolite $\Delta^{9}$-THC and the nonpsychoactive CBD (Figure 3), are the two major cannabinoids present in various concentrations in the different Cannabis chemovars, which largely determine their potency and pharmaceutical properties. The psychoactive and medicinal properties of Cannabis have been known for more than 5,000 years in the Middle East and Egypt, and later in China, India, Ancient Greece, and the Roman Empire (Di Marzo, 2008; Russo et al., 2008; Mechoulam and Parker, 2013; Farag and Kayser, 2015). $\Delta^{9}$-THC has monopolized the interest of the Cannabis-related R\&D since its isolation in 1964 (Gaoni and Mechoulam, 1964) and total synthesis a year later (Mechoulam and Gaoni, 1965). On the other hand, CBD has recently attracted the interest of the scientific community mainly due to its, among others, antioxidant, anti-inflammatory, and analgesic properties (Morales et al., 2017). Based on such properties, it represents a model chemical structure of high potential in the synthesis of chemical analogs. In addition to $\Delta^{9}$-THC and $\mathrm{CBD}$, other major cannabinoids are the cannabichromene (CBC), cannabidiolic acid (CBDA), cannabigerol (CBG), 

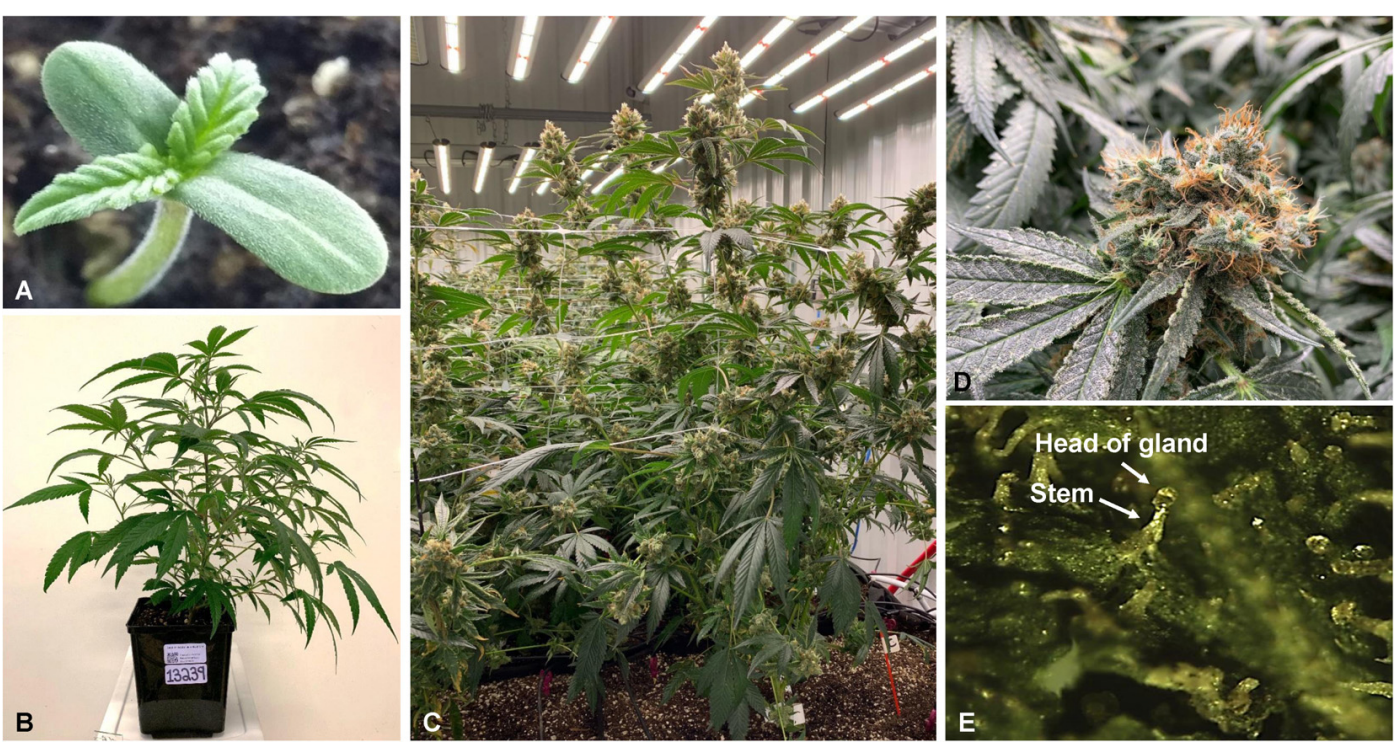

FIGURE 1 | Cannabis sativa L.; One-week old seedling of the hemp dioecious strain "Finola" (A), 4 weeks old plant of the strain "BIK" (B), and plants at the flowering stage (C). Close up photo of a flower of the strain "Skunk" (D), and big capitate-sessile trichomes as shown in the stereomicroscope (E).

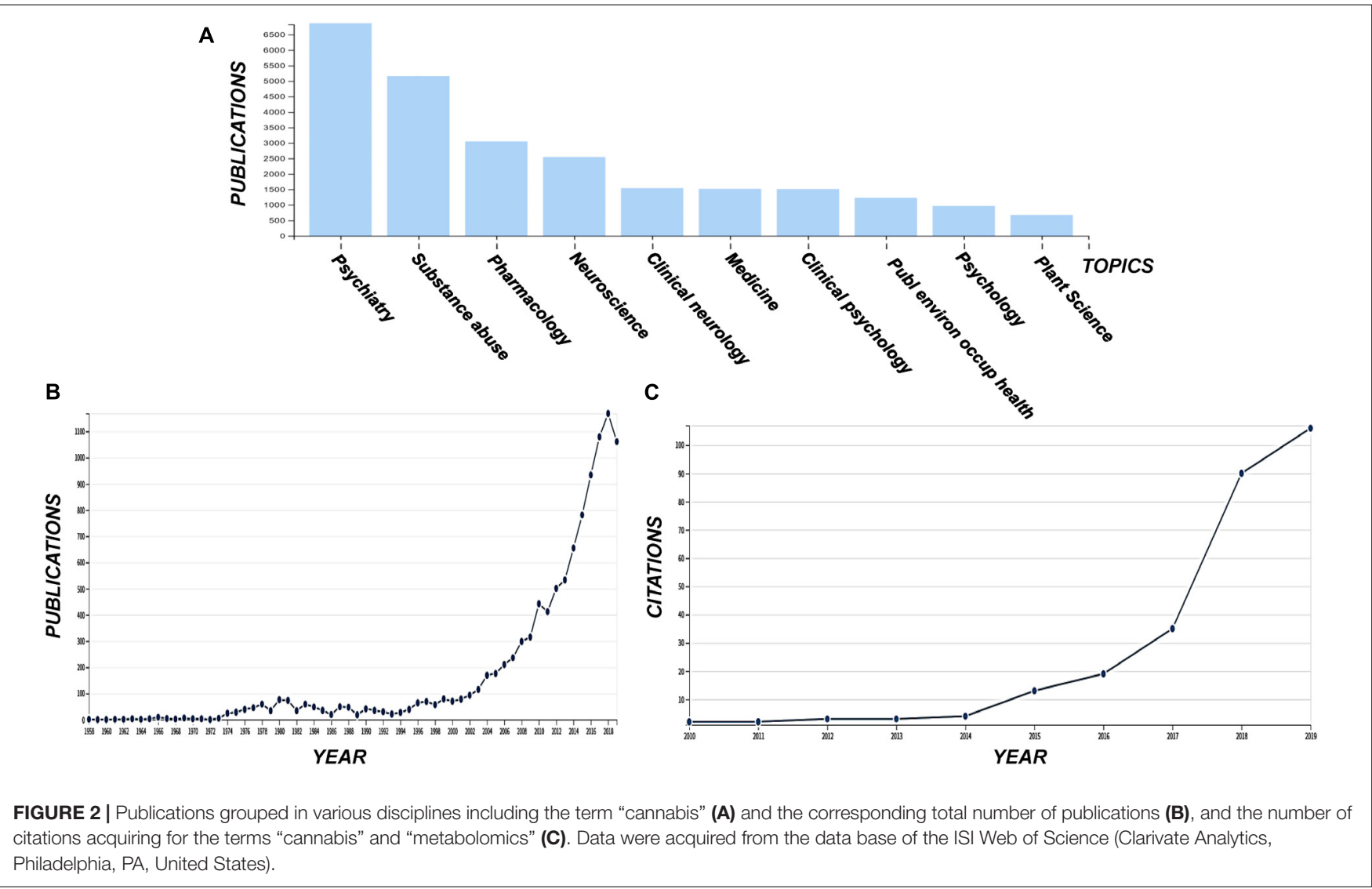

cannabinol (CBN), cannabidivarin (CBDV), cannabidivarinic acid (CBDVA), cannabigerolic acid (CBGA), cannabicyclol (CBL), $\Delta^{8}$-THC, tetrahydrocannabinolic acid (THCA), and tetrahydrocannabivarin (THCV) (Figures 3, 5).
A very interesting recent development is the biosynthesis of various cannabinoids by genetically engineered organisms, which could potentially provide solutions to the large-scale production of rare cannabinoids (Carvalho et al., 2017; 
TABLE 1 | Application of metabolomics in Cannabis research and development.

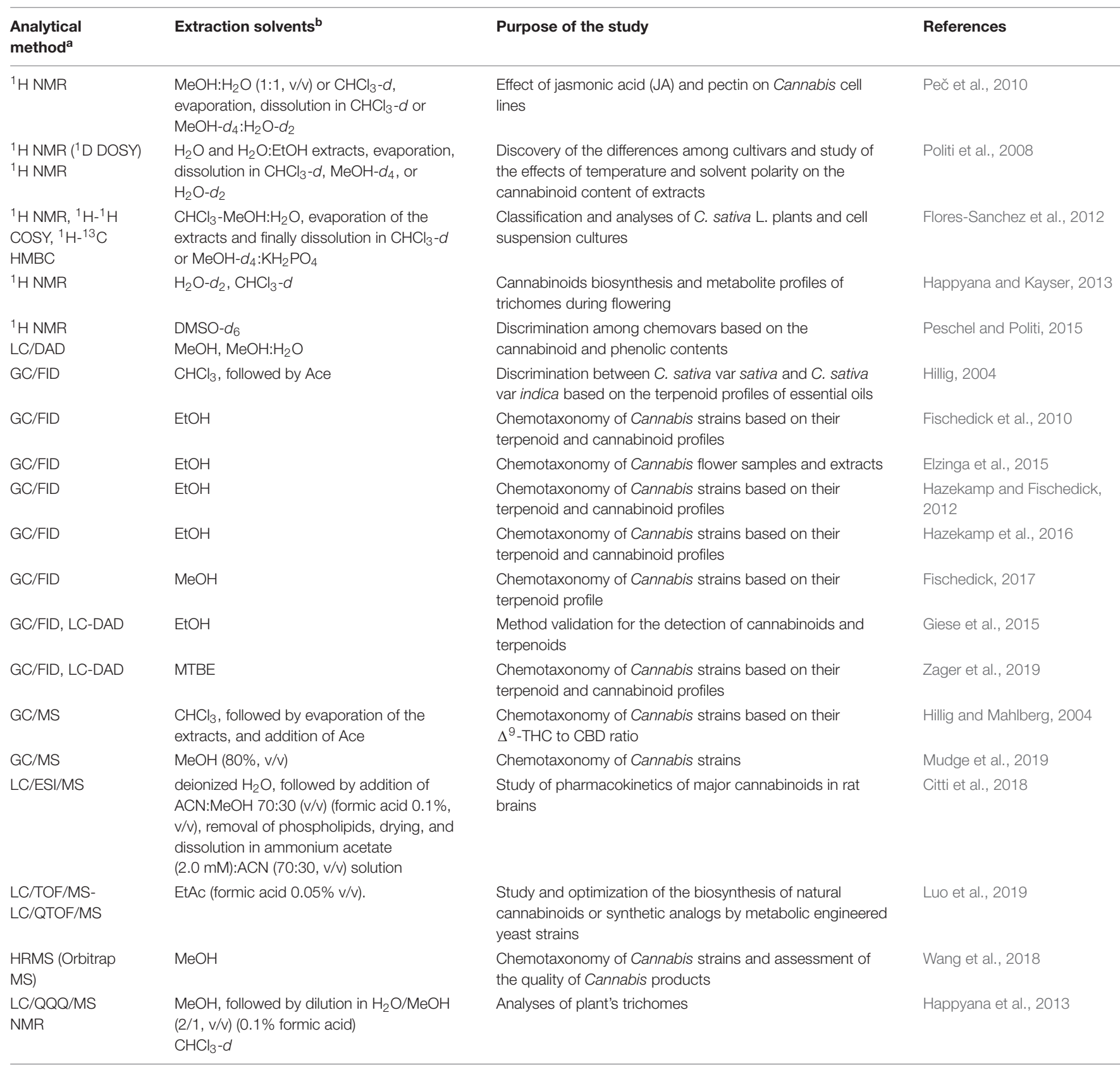

${ }^{1}{ }^{1} \mathrm{H}-\mathrm{NMR}$; proton nuclear magnetic resonance spectroscopy, ${ }^{1} \mathrm{D}$ DOSY; diffusion-edited ${ }^{1} \mathrm{H} N \mathrm{NMR},{ }^{1} \mathrm{H}-{ }^{1} \mathrm{H}$ COSY; proton/proton correlation spectroscopy, ${ }^{1} \mathrm{H}-{ }^{13} \mathrm{C}$ HMBC; ${ }^{1} \mathrm{H}_{-}{ }^{13} \mathrm{C}$ heteronuclear multiple quantum coherence, GC/FID; gas chromatography-flame ionization detector, GC/MS; GC/mass spectrometry, LC-DAD; liquid chromatography-diode array detector, LC/ESI/MS; liquid chromatography-electrospray ionization-mass spectrometry, LC/TOF/MS; liquid chromatography time-of-flight mass spectrometry, LC/QTOF/MS; quadrupole time-of-flight mass spectrometry, HRMS; high resolution mass spectrometry, LC/QQQ/MS; triple quadrupole LC/MS. ${ }^{b}$ Ace, acetone; $\mathrm{CHCl}_{3}$, chloroform; DMSO, dimethyl sulfoxide; EtAc, ethyl acetate; $\mathrm{EtOH}$, ethanol; $\mathrm{MeOH}$, methanol; MTBE, methyl tert-butyl ether.

Luo et al., 2019). The most profound example of such organism is yeast (Saccharomyces cerevisiae), which is a model that has been extensively used in metabolic engineering studies for the production of high-value chemicals (Liu et al., 2013; Nielsen et al., 2013; Carvalho et al., 2017). The biosynthesis of cannabinoids such as, CBGA, $\Delta^{9}$-tetrahydrocannabinolic acid, CBDA, $\Delta^{9}$-tetrahydrocannabivarinic acid, and CBDVA by metabolic engineered yeast strain has been recently reported
(Luo et al., 2019). In this study, the carbohydrate galactose served as the precursor of cannabinoids, and to the best of our knowledge, this is the first report on the application of metabolite profiling applying liquid chromatography time-of-flight mass spectrometry (LC/TOF/MS)-quadrupole time-of-flight mass spectrometry (LC/QTOF/MS) analysis. The extraction was performed using ethyl acetate (EtAc-formic acid $0.05 \%$, v/v). Within this context, as a functional genomics tool, metabolomics 


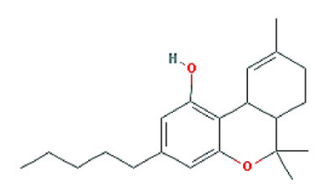

\section{$\Delta^{9}$-Tetrahydrocannabinol} (THC, 2978)

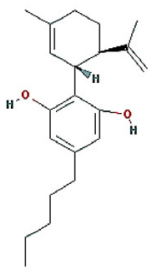

Cannabidiol (CBD, 644019)<smiles>C=C(C)C1CCC(C)=CC1(C(=O)O)c1cccc(O)c1C(=O)O</smiles>

Cannabidiolic acid (CBDA, 160570)

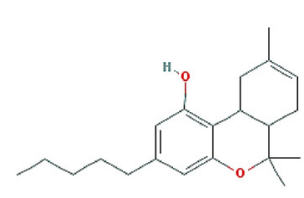

$\Delta^{8}$-tetrahydrocannabinol ( $\Delta^{8}$-THC, 2977)

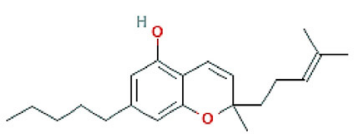

Cannabichrome (СBC, 30219)

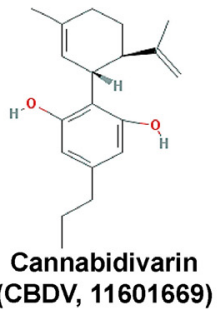

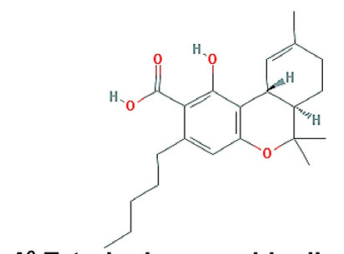

$\Delta^{9}$-Tetrahydrocannabinolic acid (THCA, 98523)<smiles>CCCCCc1cc(O)c(CC(C)=CCCC(C)C)c(O)c1</smiles><smiles>C=C(C)C1CCC(C)=CC1c1c(O)ccc(CCC)c1C(=O)O</smiles>

Cannabidivarinic acid (CBDVA, 59444387)

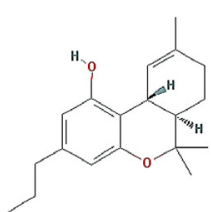

$\Delta^{9}$-Tetrahydrocannabivarin (THCV, 93147)<smiles>CCCCCc1cc(O)c2c(c1)OC(C)(C)c1ccc(C)cc1-2</smiles>

Cannabinol (CBN, 2543)

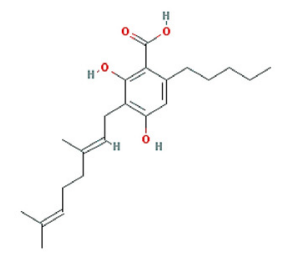

Cannabigerolic acid (CBGA, 6449999)

FIGURE $\mathbf{3}$ | Chemical structures of major Cannabis (Cannabis sativa L.) cannabinoids.

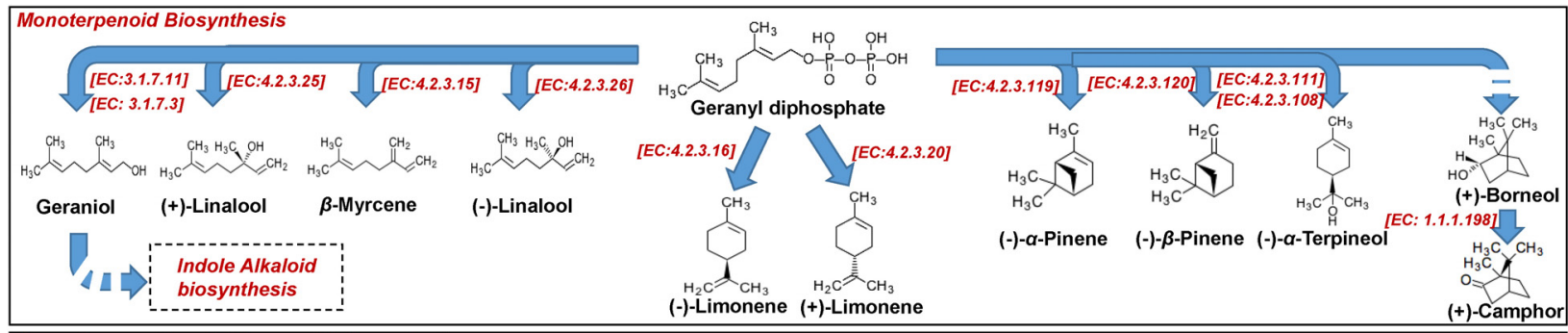

Sesquiterpenoid and Triterpenoid Biosynthesis

Sesquiterpenoids
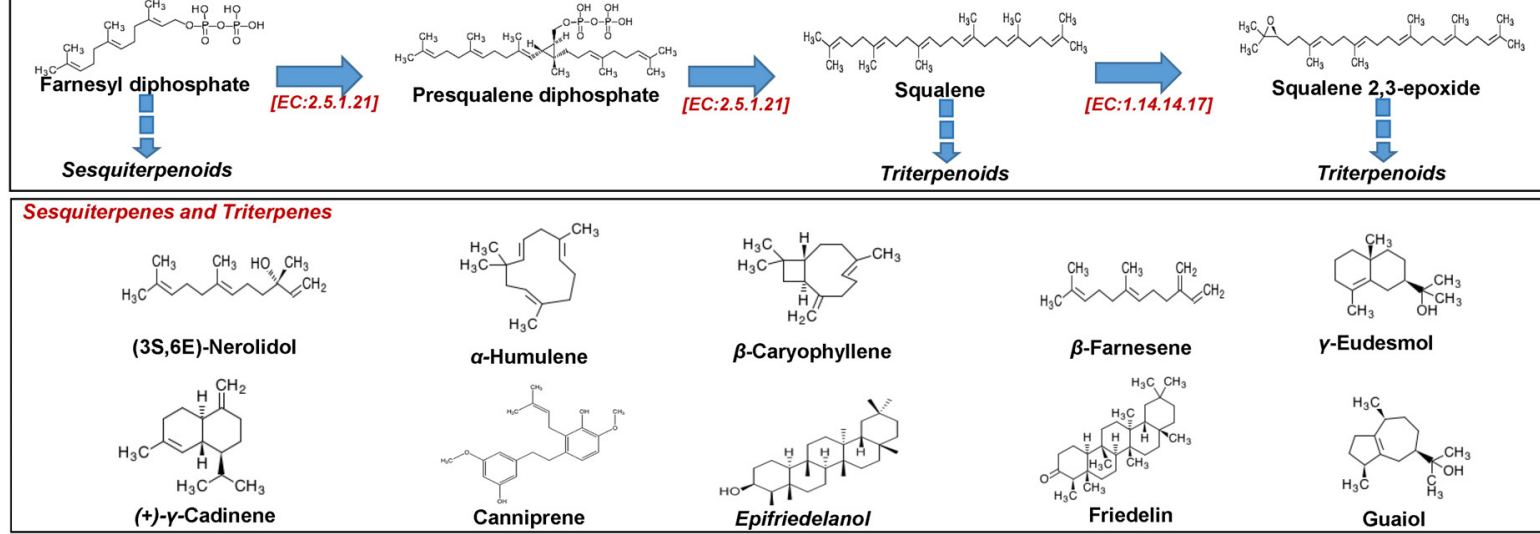

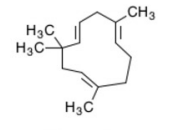

a-Humulene

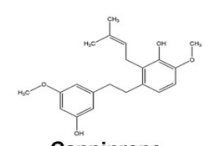

Canniprene

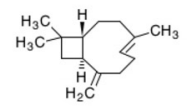

$\beta$-Caryophyllene

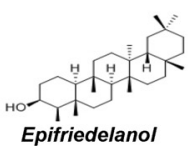

到)

$\beta$-Farnesene

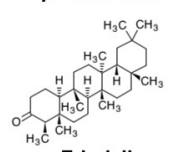

Friedelin
Triterpenoids

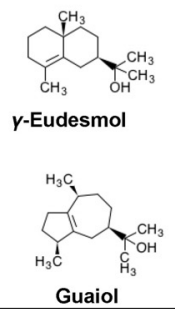

FIGURE 4 | Biosynthesis of Cannabis (Cannabis sativa L.) mono-, sesqui, and triterpenoids. 


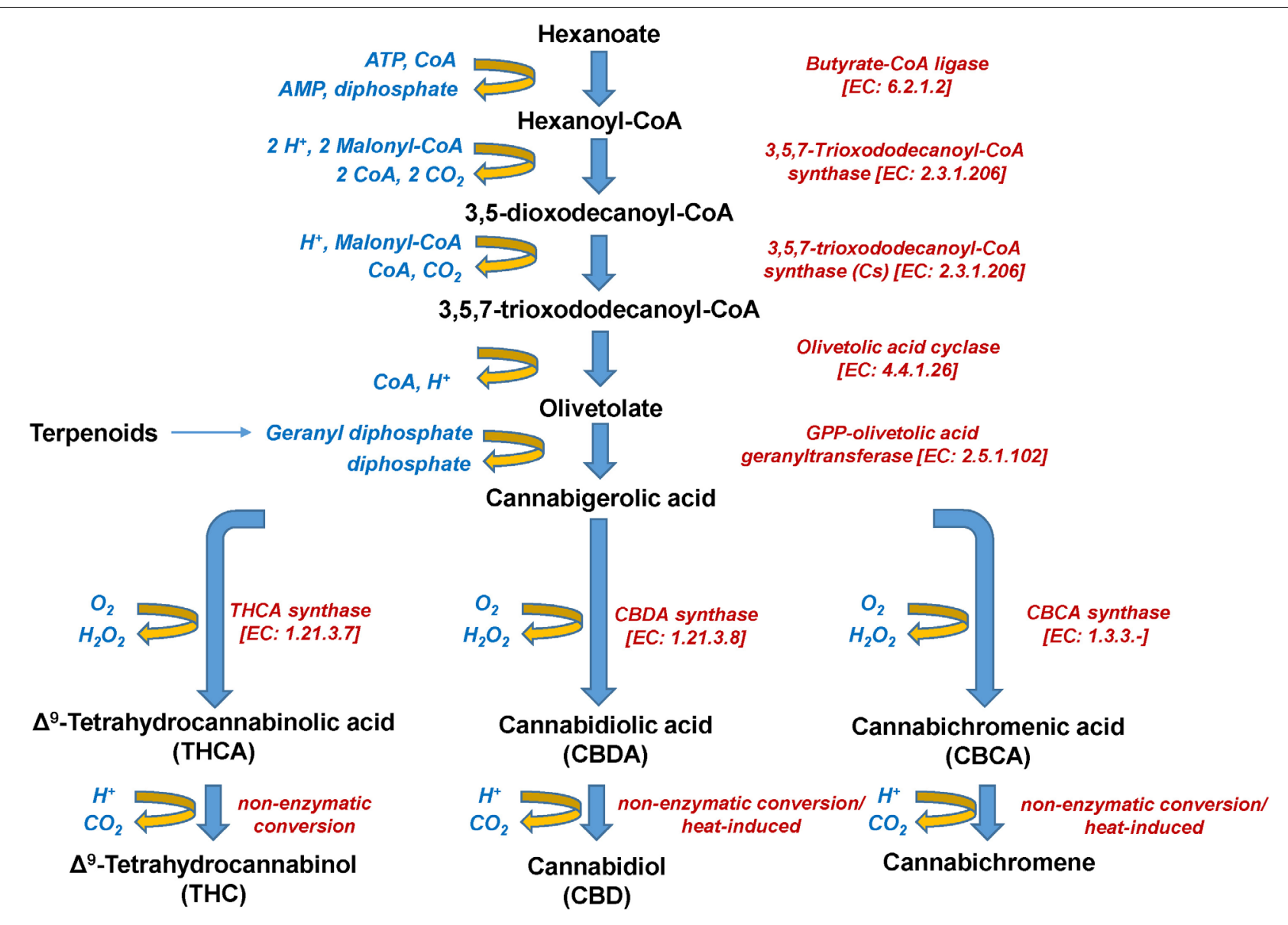

FIGURE 5 | Biosynthetic pathway of Cannabis (Cannabis sativa L.) cannabinoids.

could ideally employed in the study and monitoring of the metabolism of engineered microorganisms toward the optimization of the biosynthesis of natural cannabinoids or their synthetic analogs.

Additionally, plants biosynthesize a vast array of lipophilic volatile metabolites via the removal of hydrophilic moieties in a series of reactions (e.g., reduction, methylation, acylation) (Pichersky et al., 2006). Such plant volatiles (PVs), among others, regulate their interactions with biotic and abiotic factors (e.g., attraction of pollinators, protection against pests and pathogens) (Dudareva et al., 2013). Among PVs, terpenoids represent the most important and populated chemical group, with the sub-groups of isoprenes $\left(C_{5}\right)$, monoterpenes $\left(C_{10}\right)$, and sesquiterpenes $\left(\mathrm{C}_{15}\right)$ being the largest (Figure 4).

Terpenoids are synthesized via dimethylallyl diphosphate (DMAPP) and isopentenyl diphosphate (IPP) (Figure 4), which are derived from Cannabis biosynthetic pathways that are localized in different cell compartments (Nagegowda, 2010; Russo, 2011), sharing geranyl diphosphate (GPP) as a common precursor with cannabinoids (Grof, 2018). Playing a fundamental role in determining food's flavor and fragrance, Cannabis terpenoids have recently attracted the interest of researchers (Russo and Marcu, 2017), threatening the dominance of $\Delta^{9}$-THC and $\mathrm{CBD}$ as its main potent metabolites. As presented below, the terpenoid profiles can be used in the classification of Cannabis chemovars (Fischedick, 2017) in addition to those of cannabinoids. The transcriptomics analysis of Cannabis trichomes has revealed that the plant is capable of synthesizing all of the known terpenes (Booth et al., 2017). In this study, transcripts that are associated with the biosynthesis of terpenes were found to be highly expressed in trichomes. Their biosynthesis is regulated by terpene synthases, which are organized in large gene families and their activity is spatially and temporally distributed, making them ideal targets for engineering (Tholl, 2006). Nonetheless, the biosynthetic pathway of terpenoids is highly complex, with recent studies highlighting the roles of novel genes that encode participating enzymes (Zager et al., 2019).

Terpenoids are highly potent metabolites, affecting the behavior of animals and even humans when inhaled at very low doses, and their synergy with cannabinoids has been proposed (Russo, 2011). Studies have highlighted the cornerstone role that cannabis mono- and sesquiterpenoids play in the potency of flower extracts and the "entourage effect" (Russo and Marcu, 2017). The in-depth understanding of the mechanism of the latter, although challenging, is highly 
anticipated to provide information that could be further exploited in various applications (e.g., medicine R\&D). However, comparative study between terpenoid-rich essential oils and CBD confirmed the superior bioactivity and medicinal properties of the latter (Gallily et al., 2018). Terpenoids exhibited a transient immunosuppression and lower bioactivity levels (e.g., ROS scavenging properties) than CBD. In addition to their contribution to the properties of Cannabis extracts, individual terpenoids could be exploited per se as bioactive molecules (e.g., friedelin, canniprene, cannabisin, cannflavin A) (Russo and Marcu, 2017). For example, cannabisin B, which is isolated from the hempseed hull, has been found to induce autophagy human hepatoblastoma HepG2 cells (Chen et al., 2013).

\section{CANNABINOMICS: APPLICATIONS OF METABOLOMICS IN CANNABIS (CANNABIS SATIVA L.) RESEARCH AND DEVELOPMENT (R\&D) AND CURRENT STATE-OF-THE-ART}

Nuclear magnetic resonance (NMR) spectroscopy (Smolinska et al., 2012; Nagana Gowda and Raftery, 2016; Markley et al., 2017) and mass spectrometry (MS)-based (Hu et al., 2005; Dettmer et al., 2007; Ramautar et al., 2009; Fuhrer and Zamboni, 2015) analyzers are the two major analytical platforms employed in metabolomics analyses. Nonetheless, the integration of information on the metabolite composition of a certain sample that has been acquired by employing various analytical platforms is highly recommended, especially in the case of cannabis-derived matrices, which have highly complex metabolomes, composed of metabolites with highly diverse physicochemical properties (Figures 3-6; Andre et al., 2016).
In addition to the routine deconvolution of the composition of Cannabis flower and oil samples, there is an increasing interest on the analyses of the cannabinoid and terpenoid contents of a large array of diverse matrices such as, among others, edibles, medicine, cosmetics, blood, and urine, for research, regulatory, and law enforcement purposes (Jain and Singh, 2016; Meng et al., 2018). For the large-scale isolation of cannabinoid and terpenoid fractions or individual metabolites, the supercritical fluid extraction (SFE) and solid phase extraction (SPE) are the main employed methods (Rovetto and Aieta, 2017; GalloMolina et al., 2019). Nonetheless, for analytical and bioanalytical purposes, various extraction protocols have been proposed, with solid-based (e.g., solid-phase microextraction, SPME) and solvent-based (e.g., dispersive liquid-liquid microextraction, DLLME) ones being the preferred (Jain and Singh, 2016; Pellati et al., 2018; Ramirez et al., 2019; Atapattu and Johnson, 2020). Focusing on Cannabis metabolomics, the choice of the extraction protocol depends on the analytical platform and the aim of a given study (Table 1); in NMR analyses, chloroform $\left(\mathrm{CHCl}_{3}\right)-d$, methanol $(\mathrm{MeOH})-d_{4}$, or $\mathrm{H}_{2} \mathrm{O}-d_{2}$ are the preferred solvents, ethanol $(\mathrm{EtOH})$ for gas chromatographyflame ionization detector platform (GC/FID), $\mathrm{MeOH}$ for LC, and various solvents have been used in GC/MS-based studies. Further optimization of a given bioanalytical protocol (e.g., extraction, QC measures, analytical conditions, bioinformatics software) can lead to improved analytical capacities.

The capacity of NMR platforms in the recording of primary and secondary metabolites, and the integration of data acquired in various operating modes [e.g., proton NMR $\left({ }^{1} \mathrm{H}-\mathrm{NMR}\right),{ }^{13} \mathrm{C}-\mathrm{NMR}$, proton/proton correlation spectroscopy $\left({ }^{1} \mathrm{H}-{ }^{1} \mathrm{H}-\mathrm{COSY}\right)$, heteronuclear multiple quantum coherence (HMQC), heteronuclear multiple bond correlation (HMBC)] for the structure elucidation of complex metabolites, represent major advantages in Cannabis R\&D (Choi et al., 2004). The lyophilization is an important step in the pipeline of NMR

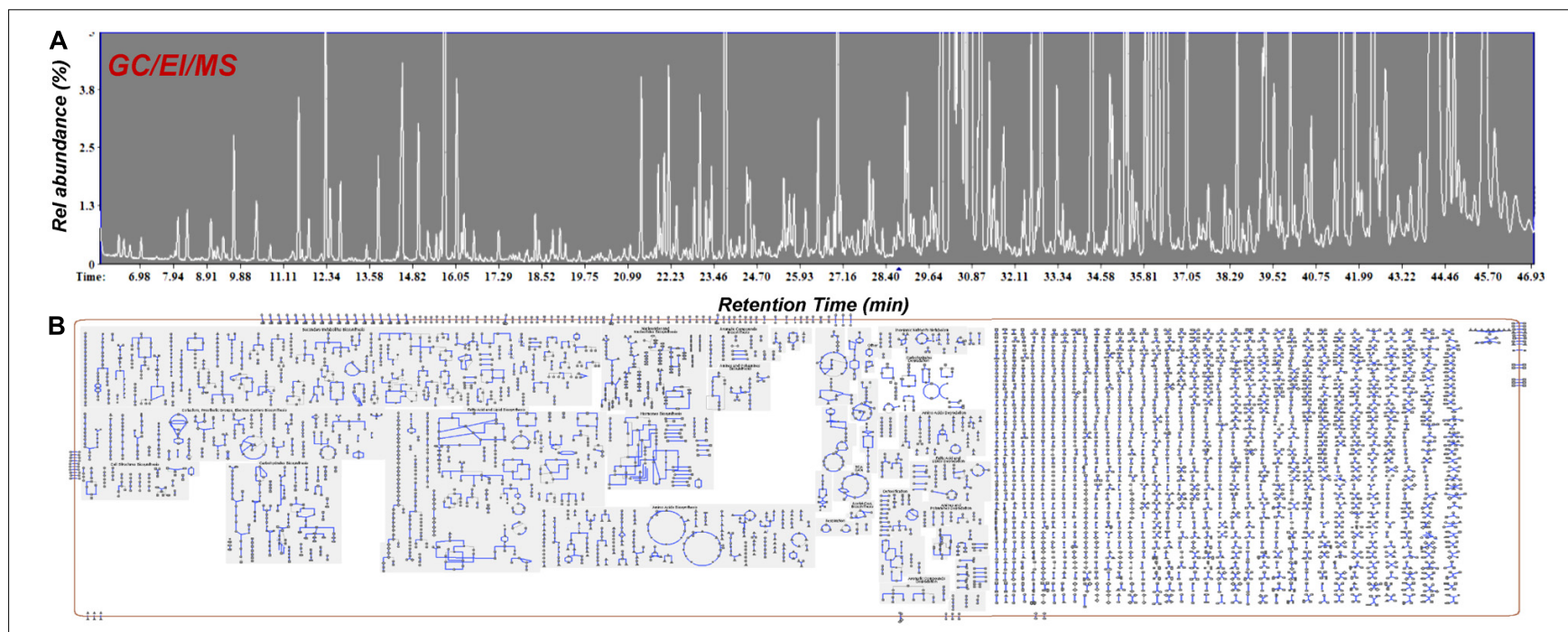

FIGURE 6 | GC/EI/MS (A) total ion chromatograms of Cannabis sativa L. var Finola flower extracts. Approximately 220 metabolite features were discovered and (B) Cellular overview of the metabolite composition of Cannabis using the Plantcyc tools (Karp et al., 2009; Caspi et al., 2015). 
analyses for the removal of water from the samples. NMR metabolomics has been applied in the classification and analyses of C. sativa L. plants and cell suspension cultures based on the recorded profiles of primary and secondary metabolites (FloresSanchez et al., 2012). In this study, following lyophilization, an indirect fractionation protocol was applied, which involves extraction of the dry plant material in a biphasic system $\left(\mathrm{CHCl}_{3}\right.$ $\mathrm{MeOH}: \mathrm{H}_{2} \mathrm{O}$ ), evaporation of the extracts and finally dissolution in $\mathrm{CHCl}_{3}-d$ or $\mathrm{MeOH}-d_{4}: \mathrm{KH}_{2} \mathrm{PO}_{4}$. A similar methodology has been applied in the study of the effects of jasmonic acid (JA) and pectin on two cell lines of Cannabis, which revealed a substantial impact of the treatments on the cells' metabolism (Peč et al., 2010). In a first step, extraction of the lyophilized material was performed using $\mathrm{MeOH}: \mathrm{H}_{2} \mathrm{O}(1: 1, \mathrm{v} / \mathrm{v})$ or $\mathrm{CDCl}_{3}$, followed by evaporation and dissolution in $\mathrm{CHCl}_{3}-d$ or $\mathrm{MeOH}-d_{4}: \mathrm{H}_{2} \mathrm{O}-d_{2}$.

In another study, the potential of diffusion-edited ( ${ }^{1} \mathrm{D}$ DOSY) ${ }^{1} \mathrm{H}$ NMR metabolomics in the assessment and optimization of extraction protocols was investigated (Politi et al., 2008). The developed protocol enabled the recording of metabolite profiles of $\mathrm{H}_{2} \mathrm{O}$ and $\mathrm{H}_{2} \mathrm{O}$ :EtOH extracts that could be used to discover differences among cultivars and the effects of parameters, such as temperature and solvent polarity on the cannabinoid content of extracts. Furthermore, ${ }^{1} \mathrm{H}$ NMR, using deuterated dimethyl sulfoxide (DMSO- $d_{6}$ ) as the extraction solvent, has a proven capacity and potential in the high-throughput discrimination between Cannabis chemovars, following chemotaxonomy approaches. Its integration with liquid chromatography-diode array detector (LC/DAD) analyses has enabled the discrimination among four chemovars based on their cannabinoid and phenolic contents (Peschel and Politi, 2015).

Cannabinoids can be analyzed by employing both GCand LC-based analyzers (Giese et al., 2015; Leghissa et al., 2018b). However, issues with their conversion under the high temperatures of the injection port of the former, make their absolute quantification tricky, and their analyses preferable by using LC-based analyzers. On the other hand, although terpenoids can be recorded by EI detectors, their structural similarities make their absolute identification challenging. Thus, GC/FID platforms are suitable for the analyses of terpenoid profiles (Giese et al., 2015; Leghissa et al., 2018b). Additionally, the linear range of the detector facilitates the recording of the wide range of terpene concentrations in Cannabis extracts. The aforementioned, make its employment important in the recording of terpenoid profiles and the assessment of the bioactivity and potency of the analyzed samples.

Furthermore, analyzers equipped with triple quadrupole (QQQ) detectors such as LC/QQQ/MS and GC/QQQ/MS systems, are very important in Cannabis research due to their superior selectivity and sensitivity in quantitative analyses (Leghissa et al., 2018b; Ramirez et al., 2019). The ability to operate these detectors in different modes such as, multiple reaction monitoring (MRM) or selected reaction monitoring (SRM), represents an advantage for Cannabis metabolomics. MRM is the most commonly employed method for the quantification and identification of metabolite features, owning its potential to the sensitivity, linear dynamic range, and specificity (Leghissa et al., 2018a). However, their performance declines during the analyses of large numbers of metabolites. Such disadvantage could be addressed by the employment of time-of-flight analyzers (ToF), which offer superior mass resolution and accuracy, facilitating fast scan speeds and enable the deconvolution of overlapping analytes (Beale et al., 2018). Furthermore, two-dimensional gas chromatography $(\mathrm{GC} \times \mathrm{GC})$ systems could improve the separation of co-eluting metabolites (Mondello et al., 2008; Beale et al., 2018) and improve our capacities in deconvoluting complex Cannabis-derived matrices.

Interestingly, during the injection of cannabinoid-containing samples in GC-based systems, their acidic forms (e.g., THCA, CBDA, CBCA) entirely convert (decarboxylation) to their neutral products (e.g., $\Delta^{9}$-THC, CBD, CBC) (Figure 5). This is probably the result of the high temperatures being applied in the injector, which commonly exceed $260^{\circ} \mathrm{C}$. Although EI coupled with GC/MS analyzers seems to be more efficient than APCI or ESI in cannabinoid analysis due to the improved fragmentation (Leghissa et al., 2018b), the observed conversions could possibly result in the recording of false-positives for $\Delta^{9}$-THC, CBD, or $\mathrm{CBC}$. This, in turn, jeopardizes analyses, posing serious risks toward the successful QC and the validity of research results. Such conversions can be avoided by appropriate silylation of the analyzed samples (Leghissa et al., 2018a) and further measures such as the use of isotopically-labeled standards, could greatly improve the accuracy of analyses.

For QC purposes, the implementation of different analyzers is required for the monitoring of metabolites across the various groups of Cannabis metabolites, which exhibit highly diverse physicochemical properties, making their detection and quantification challenging tasks. The employment of LC-diode array detector (LC-DAD) and GC/FID platforms have enabled the repeatable detection of cannabinoids and terpenes with low relative standard deviations (RSDs), using EtOH for extraction (Giese et al., 2015).

Additionally, high-resolution mass spectrometry (HRMS) [e.g., Fourier-transform ion cyclotron resonance (FT-ICR)-MS, Orbitrap analyzers] represents one of the latest developments in analytics. Commonly hyphened with LC, HRMS analyzers facilitate the coverage of a larger portion of the metabolite composition of the analyzed samples than that achieved by the conventional analyzers. Although optimization of the analytical conditions is required (e.g., binning, resolving powers), HRMS has a great potential in the chemotaxonomy of Cannabis chemovars and the assessment of the quality of Cannabis products (e.g., potency, authentication) (Wang et al., 2018).

\section{Dissection of the Cannabinoid Biosynthesis by the Glandular Trichomes}

Cannabinoids naturally occur in plants in the acidic form, with their corresponding decarboxylated analogs being the result of non-enzymatic catalyzed reactions during their storage or heating (Figure 5). The olivetolic acid cyclase (OAC, EC 4.4.1.26) is a unique type III polyketide synthase (PKS) and key enzyme in the cannabinoid biosynthetic pathway (Morita et al., 2019) together with a tetraketide synthase (C. sativa TKS; CsTKS) (Taura et al., 2009). OAC is a dimeric $\alpha+\beta$ barrel (DABB) 
protein, which exhibits structural similarities to polyketide cyclases of Streptomyces sp. (Gagne et al., 2012). Interestingly, it is the only known plant polyketide cyclase that can accept directly a linear poly- $\beta$-ketide intermediate, which is required for the biosynthesis of olivetolic acid (OA) (Marks et al., 2009; Gagne et al., 2012; Morita et al., 2019). The enzyme is overexpressed in the glandular trichomes (Gagne et al., 2012) and its structure has been recently studied (Yang et al., 2016). OA, in turn, forms the polyketide nucleus of cannabinoids (Figure 5). The precursor of cannabinoids hexanoyl-CoA, has been primarily detected in female Cannabis flowers by employing LC-MS/MS, with lower amounts recorded in the leaves, stems, and roots (Stout et al., 2012). Such pattern follows the accumulation of the end-products of cannabinoids. Hexanoyl-CoA can be synthesized via the de novo biosynthesis of fatty acids or the breakdown of lipids. Nonetheless, the potential of metabolomics in the dissection of PKS and the discovery of the functional links between the Cannabis genome, transcriptome, and metabolome is largely unexploited.

The plant has a variety of non-glandular and glandular trichomes on its flowers, which are the production sites of phytochemicals; the biosyntheses and accumulation of cannabinoids and essential oils take place in the glandular trichomes, where a terpene-rich resin is produced (Figure 1E). Three types of glandular trichomes occur in Cannabis; capitatestalked (Figure 1E), capitate-sessile, and bulbous trichomes. The development of the secretory cavities and the fine structure of trichomes have been thoroughly examined in the course of flowering by transmission electron microscopy (TEM) (Kim and Mahlberg, 1991) and scanning electron microscopy (SEM) (Happyana et al., 2013). There are two major groups of glandular trichomes, the first includes those with glands whose heads are composed of eight cells and the second, glands whose heads are usually composed of two cells, with a maximum of four (Dayanandan and Kaufman, 1976).

The superior capacity of metabolomics in the deconvolution of complex matrices is a major advantage in the study of the biosynthesis of cannabinoids by the glandular trichomes of the plant. ${ }^{1} \mathrm{H}$ NMR-based metabolomics combined with realtime PCR analyses have been employed in the study of the metabolite profiles of the trichomes of the $C$. sativa varieties Bediol, Bedica, Bedrobinol, and Bedrocan, during the last 4 weeks of their flowering (Happyana and Kayser, 2013). In the chloroform extracts, the cannabinoids $\Delta^{9}$-THC, THCA, $\mathrm{CBD}, \mathrm{CBDA}$, and $\mathrm{CBCA}$ were identified, whereas in the water extracts, several amino acids, carbohydrates, and various other metabolites were detected. The similar fluctuations of the levels of cannabinoids with those of the corresponding encoding genes suggested a decline in the cannabinoid biosynthesis of the plant near the end of the flowering period. THCA and CBDA were discovered as the cannabinoids with the highest leverage in the observed fluctuation of the metabolite profiles of the trichomes. LC/QQQ/MS (solvent; $\mathrm{MeOH}$ ) and NMR analyses (solvent; $\mathrm{CHCl}_{3}-d$ ) have also revealed the presence of several major as well as minor cannabinoids in the plant's trichomes, which further confirm their importance and role in their biosynthesis (Happyana et al., 2013). The employment of these two analyzers following the developed analytical protocols resulted in the detection of the acidic forms of the metabolites, with only minor quantities of their corresponding forms detected.

Such studies highlight the potential of metabolomics in the determination of the optimal time of harvesting of a given strain under specified conditions in order to improve the yield and quality of the obtained products.

\section{Chemotaxonomy of Varieties: Chemovars}

The domestication of Cannabis and the, until recently, illegal status of its cultivation, have resulted in a vast number of genotypes, which exhibit largely unknown properties and genotypic and metabolic backgrounds (Mudge et al., 2018). Although from a botanical perspective, the conventional taxonomy classification system is relevant, focusing on Cannabis, the taxonomy of its strains based on their content in potent metabolites (e.g., cannabinoids, terpenoids) in the so-called chemovars, seems to be the most appropriate for R\&D purposes. A data survey suggests that there has been a steady trend in favor of higher $\Delta^{9}$-THC content in herbal and resin samples; from 13 to $23 \%$ in mid-2016, compared to $7-10 \%$ in 2009 . That indicates a biased selection in favor of high potency chemovars of medicinal Cannabis (Dujourdy and Besacier, 2017). The differentiation between chemovars in their cannabinoid content is explained by the differences in the expression of genes that encode their biosyntheses (Van Bakel et al., 2011). To date, GC/FID platforms have been mainly employed in chemotaxonomy studies on Cannabis.

Cannabis strains are grouped in three types, Type I (high $\Delta^{9}$-THC content), Type II (various $\Delta^{9}$-THC to CBC ratios), and Type III (high CBD content) (Lewis et al., 2018). However, since additional Cannabis metabolites are bioactive, with a major group being the terpenoids, the classification of chemovars that takes into account the sum of its bioactive components has also been proposed (Hazekamp and Fischedick, 2012; Hazekamp et al., 2016; Fischedick, 2017), and probably best describes their properties.

Employing a GC/FID platform for the chemotaxonomy of high $\Delta^{9}$-THC-producing Cannabis strains, and using $\mathrm{MeOH}$ as the extraction solvent (Fischedick, 2017), the application of multivariate analysis enabled their grouping into 13 chemovars based on their terpenoid profiles. GC/MS has been employed in the classification of $C$. sativa var sativa or $C$. sativa var indica strains based on their $\Delta^{9}$-THC to CBD ratio (Hillig and Mahlberg, 2004). Samples were extracted in $\mathrm{CHCl}_{3}$, followed by evaporation of the extracts and finally, addition of acetone (Ace). Most chemovars with $\Delta^{9}-\mathrm{THC} / \mathrm{CBD}$ ratio greater than $25 \%$ were grouped as C. sativa var indica, while those with a ratio lower than $25 \%$ as $C$. sativa var sativa. Additionally, there was a high correlation between the content of chemovars in tetrahydrocannabivarin (THCV) and cannabidivarin (CBDV) and their grouping as C. sativa var indica.

Additionally, the terpenoid profiles can be used in the chemotaxonomy of the various Cannabis chemovars. Plants of diverse genetic backgrounds of $C$. sativa var sativa and 
C. sativa var indica, can be discriminated based on the terpenoid profiles of their essential oils using a GC/FID platform (Hillig, 2004). Plant material was extracted in $\mathrm{CHCl}_{3}$, followed by extraction in Ace. Employing the same analyzer, Cannabis terpenoids and cannabinoids following the extraction of plant material with $\mathrm{EtOH}$, were quantitatively analyzed for the classification of 11 strains into chemovars (Fischedick et al., 2010). The profiling based on 36 compounds was successful in discriminating the varieties applying multivariate analysis. Based on a similar bioanalytical protocol, employing LC-DAD and GC/FID analyzers, nine strains of commercial Cannabis were grouped in C. indica-dominant and C. sativa-dominant, based on their cannabinoid and terpenoid contents (Zager et al., 2019). The plant tissues were extracted using methyl tertbutyl ether and 1-octanol as the internal standard. Results of metabolite profiling were combined with results of RNA-seq for the transcriptome of the glandular trichomes. Interestingly, the study revealed similar patterns between the fluctuations of metabolite and transcript levels. Such observation confirms the applicability and potential of metabolomics in multi-level omics studies toward the understanding of the metabolism regulation, which is crucial in Cannabis research. A GC/FID analyzer and multivariate analysis were also employed in the discrimination of a large number of Cannabis flower samples and extracts into chemovars based on the analysis of their EtOH extracts (Elzinga et al., 2015). The analyzed strains exhibited variable reproducibility in the obtained metabolite profiles, with several terpenoids serving as biomarkers for the discrimination between the analyzed strains. Interestingly, it was also discovered that although quantitatively different, the chemical profiles of flowers and those of the extracts were qualitatively similar. Following a similar bioanalytical protocol using $\mathrm{EtOH}$ as the extraction solvent, 28 monoterpenoids, sesquiterpenoids, and cannabinoids were used for the classification of commercial Cannabis strains in various chemovars and the assessment of their quality (Hazekamp and Fischedick, 2012). The same research group has successfully analyzed 460 Cannabis accessions by GC/FID, aiming in their classification as "sativa" or "indica" based on their cannabinoid and terpenoid contents (Hazekamp et al., 2016). The extraction was performed using EtOH and 1octanol served as the internal standard. The chemotaxonomy of Cannabis in chemovars based on their terpenoid profiles has also been performed by headspace GC/MS analysis, using $\mathrm{MeOH}$ $(80 \%, \mathrm{v} / \mathrm{v})$ for the extraction (Mudge et al., 2019). The applied protocol enabled the grouping of the analyzed strains in 33 chemovars, with their content in the sesquiterpene caryophyllene oxide to be strongly correlated with high $\Delta^{9}$-THC content. LC hyphened to UV detectors has also been employed in the rapid grouping of strains in chemovars based on their content in major cannabinoids (Mudge et al., 2016).

\section{Cannabis as a Source of Novel and Unique Bioactive Compounds}

There is no doubt that Cannabis with the chemical diversity, unique structures (Figures 3, 4), physicochemical properties, and diverse bioactivities of its metabolites, represents an invaluable source for the development of novel applications in various sectors, such as, medicine, cosmetics, and the food industry. Although such applications are yet in their infancy, it is anticipated that Cannabis-based or Cannabis-infused products will provide solutions to major human health conditions, and lead to the development of new functional food and beverage products.

Nonetheless, the complexity of the plant's extracts and the in-depth understanding of interactions between their components (e.g., entourage effect) and synergism, represent major challenges. The development of pharmaceuticals based on Cannabis extracts is challenging for the medicinal research, which operates according to the principle "single compound-single target" (Hazekamp et al., 2016). However, the ineffectiveness of individual compound-based medicine against multigenic diseases (e.g., cancer) or diseases that affect multiple tissues dictate the need for the discovery of drugs that will act on multiple targets (Zimmermann et al., 2007; Giordano and Petrelli, 2008). Therefore, it is of paramount importance to distinguish between the bioactivities of mixtures and those of the individual bioactive metabolites based on appropriate protocols, which could be greatly assisted by high-throughput metabolomics. Examples of Cannabis-derived pharmaceuticals are displayed in the Table 2.

Within this context, the discovery, assessment, and development of new sources of bioactivity as drugs for the treatment of various conditions, represent key priorities for the

TABLE 2 | Examples of Cannabis-derived pharmaceuticals.

\begin{tabular}{|c|c|c|}
\hline Name & Active ingredients (a.i.) & Indications \\
\hline $\begin{array}{l}\text { Bedrocan }{ }^{\circledR} \\
\text { Cannabis flos } \\
\text { (dry flower from } \\
\text { various cultivars) } \\
\text { or granules }\end{array}$ & $\begin{array}{l}\text { Standardized, consistent } \\
\text { composition of } \\
\text { cannabinoids and } \\
\text { terpenes }\end{array}$ & $\begin{array}{l}\text { - Pain, spasms and } \\
\text { inflammation, often } \\
\text { associated with MS } \\
\text { - Chronic nerve pain. }\end{array}$ \\
\hline Cannador $^{\circledast}$ & $\begin{array}{l}\text { THC:CBD ratio } \\
\text { approximately 2:1 }\end{array}$ & $\begin{array}{l}\text { - Clinically tested for reduction } \\
\text { of muscle stiffness, spasms } \\
\text { and pain in Multiple Sclerosis } \\
\text { - Annorexia/cachexia in } \\
\text { cancer patients } \\
\text { - Post-operative pain } \\
\text { management. }\end{array}$ \\
\hline $\begin{array}{l}\text { Dronabinol } \\
\left(\text { Marinol }^{\oplus}\right. \\
\text { Syndros }^{\oplus} \text { ) }\end{array}$ & $\begin{array}{l}\Delta^{9} \text {-Tetrahydrocannabinol } \\
\left(\Delta^{9} \text {-THC) (synthetic }\right. \\
\text { cannabinoid) }\end{array}$ & $\begin{array}{l}\text { - Nausea and vomiting } \\
\text { associated with cancer } \\
\text { chemotherapy } \\
\text { - Loss of appetite and weight } \\
\text { loss in people with HIV } \\
\text { infection } \\
\text { - Sleep apnea reliever }\end{array}$ \\
\hline $\begin{array}{l}\text { Nabilone } \\
\left(\text { Cesamet }^{\circledR},\right. \\
\left.\text { Canemes }^{\circledR}\right)\end{array}$ & $\begin{array}{l}\text { Nabilone (synthetic } \\
\text { cannabinoid) }\end{array}$ & $\begin{array}{l}\text { - Nausea and vomiting } \\
\text { associated with cancer } \\
\text { chemotherapy }\end{array}$ \\
\hline Sativex ${ }^{\circledR}$ & $\begin{array}{l}\Delta^{9}-\mathrm{THC} 27 \mathrm{mg} \mathrm{mL} \mathrm{L}^{-1} \\
\text { (from Tetranabinex- } \\
\text { Cannabis sativa L. } \\
\text { extract) } \\
\text { cannabidiol (CBD) } 25 \mathrm{mg} \\
\mathrm{mL}^{-1} \text { (from Nabidiolex - } \\
\text { C. sativa L. extract) }\end{array}$ & $\begin{array}{l}\text { - Treatment for the } \\
\text { symptomatic relief of } \\
\text { neuropathic pain in multiple } \\
\text { sclerosis (MS) in adults }\end{array}$ \\
\hline
\end{tabular}


medicinal R\&D (Chin et al., 2006; Dittrich and Manz, 2006; Harvey, 2008). Based on results of recent research, there is a growing amount of evidence that supports the effectiveness of various Cannabis-derived cannabinoids in the treatment of a wide range of conditions, including, among others, chronic and acute pain, epilepsy, sleep disorders, multiple sclerosis, gastrointestinal reflux disease, irritable bowel syndrome (IBS), spasticity, hypertension, and schizophrenia (Pacher et al., 2005; Hazekamp and Grotenhermen, 2010; Caraceni et al., 2014; Bruni et al., 2018).

The psychoactive and medicinal properties of Cannabis have been known for more than 5 millennia by major civilizations of the Middle East, Egypt, China, India, Ancient Greece, and the Romaine Empire (Di Marzo, 2008; Mechoulam and Parker, 2013; Farag and Kayser, 2015). Cannabinoids were the first identified group of potent Cannabis metabolites, with the medicinal properties of its major representatives being attributed to their interference with the $\mathrm{G}$ protein-coupled cannabinoid receptors (GPCRs) CB1 and CB2 of the endocannabinoid system (Di Marzo et al., 2004; Mechoulam and Parker, 2013). The CB1 receptors are amongst the most abundant GPCRs in the brain of mammals and are also present, to a lesser extent, in various peripheral organs, whereas the $\mathrm{CB} 2$ receptors have been identified throughout the central nervous system (CNS) and cells of the immune system, being part of a general protective system (Di Marzo et al., 2004; Di Marzo, 2008; Mechoulam and Parker, 2013) and modulating cytokine release (Pertwee, 2005).

Although $\Delta^{9}$-THC was isolated and synthesized in the mid 60s' (Gaoni and Mechoulam, 1964; Mechoulam and Gaoni, 1965), the research on the mode(s)-of-action (MoA) of cannabinoids remained inconclusive for more than 20 years (Mechoulam and Parker, 2013). The similarities between the physicochemical properties and structures of cannabinoids (Figure 3), pose an obstacle toward their isolation in pure chemical form (Mechoulam and Hanuš, 2000) and the subsequent investigation of their bioactivities, MoA, and pharmacokinetics.

Furthermore, the cannabinoid interconversions during storage and heating are complex (Figure 5), which represents a major challenge for the development of new Cannabis-based products, such as drugs, cosmetics, beverages, and edibles. Additionally, of great interest is the fact that non-psychoactive Cannabis metabolites (e.g., terpenoids) can act synergistically with $\Delta^{9}$-THC, contributing to the so-called "entourage effect" of medicinal Cannabis extracts (Ben-Shabat et al., 1998; Russo, 2011, 2018), with the undergoing operating mechanism(s) being largely unexplored.

Another major challenge for the Cannabis industry related to drug development is the production of standardized extracts that will meet the standards set by the corresponding regulatory agencies (e.g., Cannabis Act, Canada) ${ }^{1}$. The agricultural practices, plant growth conditions, and extraction processes all play key roles in achieving consistency of the extracts' content, however, discussion on those factors are beyond the aim of the present review. The robust QC of Cannabis preparations and assessment

${ }^{1}$ https://laws-lois.justice.gc.ca/PDF/C-24.5.pdf of their consistency and potency could be achieved by applying metabolomics for the various batches of a given product. The application of metabolomics employing and integrating information acquired by various analyzers (e.g., LC and GCbased platforms) could lead to the deconvolution of the complex chemical composition of Cannabis extracts and the monitoring of the consistency across batches, facilities, and different cultivation periods. For R\&D purposes, metabolomics could be employed in the optimization of agricultural practices, growth conditions, and extraction processes in order to achieve the desired composition of extracts with proven medicinal properties, as discussed below. To the best to our knowledge, such approach is in its infancy, and no reports are currently available.

Cannabinoids exert palliative effects in cancer patients by, among others, preventing nausea and pain, and stimulating appetite (Guzman, 2003). Additionally, it has been shown that they inhibit the growth of tumor cells in vitro and in vivo in animal models (Guzman, 2003) and exhibit antitumor activity (Velasco et al., 2012; Dando et al., 2013). Such bioactivities have been supported by Phase III clinical trials, however, the corresponding mechanism(s) of action remain inconclusive. In the case of pancreatic adenocarcinoma it seems that cannabinoids induce autophagy and inhibit cell growth (Dando et al., 2013).

CBD, the second-most studied cannabinoid, and various of its synthetic derivatives have attracted the interest of the pharmaceutical industry and that of academic researchers, with specific focus on the understanding of their MoA, potency, and pharmacokinetics (Morales et al., 2017). It exhibits remarkable potency, including sedative, anxiolytic, anticonvulsive, hypnotic, anti-psychotic, anti-nausea, and antiinflammatory effects (Mechoulam et al., 2002). Preclinical studies have highlighted the inflammatory potential of CBD in mouse models (Morales et al., 2017), without causing behavioral changes (Viudez-Martínez et al., 2018). It exerts a well-documented anti-seizure and anti-epileptogenic properties against epilepsy independent of the CB1/CB2R, which is supported by Phase III clinical trials on treatment-resistant epilepsies (Rosenberg et al., 2017). Additionally, information on the action of $\Delta^{9}$ THC containing Cannabis preparations in the treatment of pediatric epilepsies remains largely fragmented (Rosenberg et al., 2017). On the other hand, $\Delta^{9}$-THC or synthetic cannabinoidinduced seizures in mice have been observed following their intraperitoneal administration, which can be prevented by a CB1-selective antagonist (Malyshevskaya et al., 2017).

In addition to the two major cannabinoids $\Delta^{9}$-THC and CBD, other cannabinoids with limited or no psychoactive properties could exhibit interesting pharmaceutical properties and bioactivities. Among those are cannabidiol and cannabinoic acids, whose MoA are yet unknown (Di Marzo et al., 2004). Several cannabinoids (e.g., $\Delta^{9}$-THC, CBD, CBC, CBG, CBN), exhibit antibiotic activity to Staphylococcus aureus, highly correlated to the stereochemistry of the molecules and the groups of substitution (Appendino et al., 2008).

Additionally, the biotransformation of cannabinoids in the human body, which determines their potency and medicinal properties, is a largely unexplored topic and could lead to the discovery of novel bioactive metabolites (Dinis-Oliveira, 
2016). Due to their high lipophilicity, cannabinoids could remain in the plasma and fat tissue for prolonged periods. Focusing on the $\Delta^{9}$-THC, in a first phase (Phase I, oxidative metabolism), it is metabolized to 11 -hydroxy- $\Delta^{9}$-THC, which is further metabolized to the inactive 11-nor-9-carboxy- $\Delta^{9}$ THC. The Phase II (conjugation metabolism), includes reactions such as conjugation which lead to the detoxification of the molecule (Dinis-Oliveira, 2016). More than $80 \Delta^{9}$-THC-derived metabolites have been identified as products of its transformation (Mazur et al., 2009).

The integration of information from clinical trials in which patients provide feedback following treatments with various Cannabis chemovars and information on the corresponding metabolite profiles employing metabolomics is very important for the selection of the best varieties and their standardization for medical use and drug discovery purposes. Based on this approach, applying GC/FID/MS metabolomics, Dutch researchers evaluated 460 accessions based on their content in major cannabinoids and terpenes (Hazekamp et al., 2016). Results revealed a strong correlation between Cannabis phenotypes and their terpene content, as it can be evaluated by their smell, taste, and medicinal properties, as well the importance of gibberellic acid (GAs) in terpenoid biosynthesis.

LC/ESI/MS-based metabolomics has been employed in the study of pharmacokinetics of major cannabinoids in rat brains, following their oral administration (Citti et al., 2018). Brains were initially homogenized in deionized $\mathrm{H}_{2} \mathrm{O}$, followed by the addition of ACN:MeOH 70:30 (v/v) containing formic acid $(0.1 \%, \mathrm{v} / \mathrm{v})$. Following the removal of phospholipids, the extracts were dried and finally an ammonium acetate $(2.0 \mathrm{mM})$ :acetonitrile (70:30, $\mathrm{v} / \mathrm{v})$ solution was added. Analysis revealed the formation of novel, unique $\mathrm{CBD}$-derived metabolites and fluctuations in the levels of several other endogenous metabolites as a result. Such application confirms the potential of metabolomics in the acquisition of fundamental knowledge related to the study of the mode(s)-of-action and bioactivity of cannabinoids for medical purposes.

The function of the endocannabinoid system and its regulation by endocannabinoids are complex, and yet relative information is largely fragmented. Their levels and relative composition vary depending and their role, which could shift from protective to deregulator of the physiological state of an individual. Therefore, compounds that could prolong the lifespan or suppress endocannabinoids could be extremely important in treating various conditions (Di Marzo, 2008).

\section{Cannabis in the Food Industry: Exploring the Potential and Assessing the Associated Risks}

Canada (Federal level) (Cox, 2018), the United States of America (Individual States) (Pacula and Smart, 2017), and Uruguay, have pioneered the legislation on Cannabis use for medicinal and recreational purposes. In contrast to the research on the plant as a source of bioactivity for applications in medicine as described above, the corresponding research on its use as a food ingredient is in its first steps (Charlebois et al., 2018). A wide variety of methods exist for consuming Cannabis edibles for medical purposes such as, concentrated oils, tinctures, and oil capsules, whereas from a recreational perspective, edibles could be considered cannabis-infused food products and beverages, with the latter being less popular (Blake and Nahtigal, 2019).

Food metabolomics, or foodomics, has established itself as a robust and precise bioanalytical tool in the assessment of quality and safety of raw materials and food products, as well as in the assessment and optimization of processing protocols and procedures (Wishart, 2008; Cevallos-Cevallos et al., 2009; Herrero et al., 2012; Castro-Puyana and Herrero, 2013). MSbased analytical platforms hyphened with various detectors and NMR have been employed in food research and also the routine QC of food products (Cevallos-Cevallos et al., 2009; Ibáñez et al., 2013). Food samples could be solid, semi-solid or liquid, and they are composed of a vast number of compounds such as, small molecular weight metabolites (e.g., amino acids, carbohydrates, carboxylic acids, fatty acids), proteins, and peptides, thus, generating very complex matrices. In the case of Cannabis, the presence of a large number of lipophilic cannabinoids and terpenoids, together with primary and secondary metabolites, results in one of the most challenging matrices to be analyzed (Figure 6). Therefore, the analyses of cannabis-infused food becomes extremely challenging, requiring the implementation and integration of advanced analyzers.

Nevertheless, the application of advanced metabolomics in the monitoring of the global metabolite profiles of Cannabisinfused edibles and beverages could provide valuable insights into the stability of cannabinoids and other Cannabis-derived metabolites in the food matrices, their fate and interconversions during processing, and possible toxicity issues. Additionally, it could reveal the links between their organoleptic and medicinal properties, and potency with their metabolite composition, that could be further exploited in drug discovery and the development of new food products. Nonetheless, the task of developing validated protocols for the analyses of a large array of Cannabis metabolites in food matrices is challenging, and currently, only a few relative studies have been published (Escrivá et al., 2017; Meng et al., 2018). Although THC-infused food could spark public and scientific controversy, the fact that CBD exhibits interesting bioactivities, while at the same time being nonpsychoactive, possibly makes it a promising candidate for the large-scale production of functional CBD-infused edibles or beverages. However, since research in the field in its first steps, the use of cannabinoids in food should undergo thorough research and assessment prior to the commercialization of related products.

\section{Regulation of Cannabis Metabolism Toward the Optimization of the Yield and the Biosynthesis of Bioactive Products Effect of Light Conditions on Cannabis Growth:
Phenotypes and Metabolomes}

As it is the case with all plant species, the light regime is an important growth factor in Cannabis cultivation, being a fundamental component for the optimization of every successful 
growth protocol. The intensity, quality, and duration of light are among the most important factors that regulate plants' physiology, development, and morphogenesis (Burgie et al., 2014; Galvão and Fankhauser, 2015; Krahmer et al., 2018). For the processing of the information relative to light regimes, plants are equipped with a series of photoreceptors capable of sensing a broad light spectrum (280-750 nm, UV-B to farred) that are present in all of their compartments (Kami et al., 2010; Galvão and Fankhauser, 2015). Based on research using Arabidopsis as the model organism, it has been discovered that the phytochromes A-E (PhyA-PhyE) are responsible for sensing the red (R) and the far-red (FR) light, three classes of photoreceptors were assigned as sensors of the UV-A/blue light, whereas data on UV-B were inconclusive (Kami et al., 2010). An early study on Cannabis, has indicated a linear increase in the $\Delta^{9}$-THC content of leaves and flowers of medicinal chemovars with the UV-B irradiation level (Lydon et al., 1987). However, treatments had no effect on the levels of other cannabinoids in both the medicinal and industrial chemovars being studied.

In Cannabis research, among others, the in-depth understanding of its transition to the flowering stage is of great importance. Light as well as temperature, regulate the transition to the reproductive growth through their effects on the complex regulatory plant metabolic networks (Kami et al., 2010). Although evidence offers some understanding on the roles of phytochromes in plants' development and morphogenesis, information on the correlation between their function and the regulation of plants' primary and secondary metabolism is still largely fragmented. The acquisition of such knowledge represents a challenge but at the same time a great opportunity for Cannabis metabolomics. Furthermore, the recent developments related to the study of the effects of light on plants have been tremendous since the introduction of light-emitting diodes (LEDs), which are replacing the gas-discharge lamps. National Aeronautics and Space Administration (NASA) researchers discovered LEDs in their effort to grow plants in space (Stutte, 2015). LED technology enables a vast variety of light regimes to be applied on plants in order to regulate photosynthesis, morphogenesis, and growth according to our needs, with a low thermal energy output.

Experiments with tomato (Solanum lycopersicum L.) have shown that the blue and purple lights reduce photosynthesis, enhance the cyclic electron flow (CEF) and induce energy dissipation for photoprotection of the photosystems I and II (PSI and PSII, respectively) (Yang et al., 2018). The exposure of plants in different intensities of monochromatic red-LED affect their central metabolism and the size of the fruits produced (Fukushima et al., 2018). Additionally, LEDs have been reported to affect the reactive oxygen species (ROS) redox, antioxidant responses, and the in vitro regeneration of plants (Gupta and Agarwal, 2017).

The urge to improve Cannabis yield and quality has resulted in an exponentially increasing interest by the scientific community and the Cannabis industry on the study of the effects of LEDs on the plants' metabolism. The potential of LED lighting in the Cannabis sector has been recently reviewed (Lefsrud et al., 2019), in a review that confirms the lack of solid evidence on the effects of light on cannabinoid and terpenoid yields.
Treatments of Cannabis plants with high-pressure sodium (HPS) and different LED types affected their morphology but had a minor impact on their cannabinoids yields (e.g., CBG, CBD, $\Delta^{9}$-THC content), as revealed by the GC/FID analyses of the EtOH extracts (Magagnini et al., 2018). However, plants that were grown under LED light had improved $\Delta^{9}$-THC and CBD concentrations. Additionally, the study concluded that the red to far-red light ratio had no substantial effect on flowering. Based on evidence that was acquired by another study, it has been concluded that different strains exhibiting high $\Delta^{9}$-THC yield capacity are able to use high levels of photosynthetic photon flux densities (PPFDs). Such observation indicates that the chemovars being tested can be cultivated under high light intensity regimes outdoors or in the greenhouse, under controlled conditions (Chandra et al., 2015).

Nonetheless, although in the literature there is a handful of studies on the effects of environmental parameters (e.g., light, temperature) on the growth of Cannabis, there is only a few on the investigation of such effects applying metabolomics. Yet, their impact on Cannabis potency and global metabolism is largely unknown. Thus, it is highly expected that the employment of such tool could greatly assist toward the optimization and customization of growth parameters for the production of high quality and standardized products from the various Cannabis chemovars.

\section{Cannabis Plant Protection and Interactions With Biotic and/or Abiotic Factors}

Plant pathogenic fungi and pests affect the yield of Cannabis cultivations in the greenhouse and outdoors, resulting in devastating quantitative and qualitative losses (McPartland, 1996a,b). Therefore, the optimization of agricultural practices such as foliar or soil applications of registered PPPs (including bioelicitors and biological control agents), that could improve the plants' productivity and cannabinoid-biosynthetic capacity, and reduce the levels of xenobiotics in the final product (McPartland and McKernan, 2017), are of paramount importance. Such an endeavor could be accomplished through the comprehensive monitoring of plants' metabolism applying metabolomics, which has a great potential in PPPs' R\&D (Aliferis and Chrysayi-Tokousbalides, 2011; Aliferis and Jabaji, 2011). Nevertheless, Cannabis producers, and especially those applying organic farming, currently lack information and guidance on the efficient application of such products (Sandler et al., 2019).

Although the primary MoA for most a.i. of PPPs is known, information on their secondary ones, if non-existent, is largely fragmented (Casida, 2009, 2010; Aliferis and Jabaji, 2011). Although fungicides and insecticides act on functions of the target-organisms that are vital for their survival, they additionally could impact the metabolism of plants (Lydon and Duke, 1989; Garcia et al., 2003; Petit et al., 2012), with the relative knowledge on the undergoing mechanisms being limited. Within this context, the study of the effects of registered PPPs for applications in Cannabis cultivation on its metabolism and potency could contribute to the optimization of the agricultural practice (frequency, time of application in relation to the plant's 
vegetative stage, dosage) and the selection of the most efficient and safe products.

Of specific interest is the use of phytohormones and PGR, which is a group of PPPs that are integral parts of the agricultural practice for many crops. Phytohormones, in minute amounts, can substantially impact plant processes such as growth, dormancy, and flowering. Abscisic acid (ABA), is a phytohormone that plays a key role as a messenger-molecule by regulating plant responses to biotic and abiotic stimuli, including, among others, salinity, drought, heat, cold, and pathogen infections (Raghavendra et al., 2010). Its application to Cannabis at the flowering stage has shown to increase its $\Delta^{9}$-THC content, however, it causes a decrease in its chlorophyll, steroid, and sterol contents (Mansouri et al., 2009b). Gibberellic acid $\left(\mathrm{GA}_{3}\right)$, another major plant phytohormone, has shown to stimulate the biosynthesis of Cannabis terpenoids via the mevalonic acid biosynthetic pathway, but it inhibits the biosynthesis of those that are synthesized via the plastidial methylerythritol phosphate biosynthetic pathway (Mansouri et al., 2009a). Furthermore, in both sexes, GA3 application results in decreased levels of chlorophylls, carotenoids, and $\Delta^{9}$ THC. The PGR ethephon, which is used in the agricultural practice to regulate plants' metabolism (e.g., promotion of fruit ripening, flower induction, initiation of reproductive development), has shown to greatly affect the plants' metabolite composition, including their $\Delta^{9}$-THC, CBD, and terpenoid content (Mansouri et al., 2016). Although the study was inconclusive on the exact effect of the levels of ethephon on the global Cannabis metabolism, it highlighted the potential of this PGR toward the improvement of yield via the regulation of the plant's metabolism.

PGR are bioactive in very low concentrations and their bioactivity is highly correlated to factors such as the genotypes, the growth stage of the plants and their physiological condition, and environmental factors (e.g., humidity, light, temperature). Therefore, comprehensive studies are further required for the standardization of their applications in Cannabis cultivation and the determination of the optimal treatments (e.g., time, doses) under specified environmental conditions, in order to achieve optimum yield and quality.

In addition to the traditional PPPs and biological control agents, the group of endophytes is an alternative source of bioactivity for potential applications in plant protection. They are microorganisms that have developed a mutually beneficial symbiotic relationship with their host, living inside their organism, without causing symptoms (Porras-Alfaro and Bayman, 2011). Numerous Cannabis endophytes have been found to compose the Cannabis microbiome (Kusari et al., 2013; Scott et al., 2018). Such organisms could be used to increase the resistance of plants to pests and pathogens and possibly in order to modulate the biosynthesis of cannabinoids and other Cannabis potent metabolites such as the terpenoids (Gorelick and Bernstein, 2017).

\section{Biomarker-Assisted Selection in Cannabis Breeding}

Through millennia, Cannabis cultivation has spread worldwide, resulting in the generation of numerous landrace varieties (strains resulting from human and/or natural selection), and was amongst the first plant species to be domesticated (Clarke and Merlin, 2016; Rahn et al., 2016). The Cannabis gene pool has been significantly reduced due to the asexual propagation of strains exhibiting improved yields and potency, inbreeding, the lack of comprehensive germplasm collections (Clarke and Merlin, 2016), and the production of modern strains based on a limited genotypes (Rahn et al., 2016). This, in turn, has additionally resulted in the reduction of its chemical diversity (Mudge et al., 2016, 2018).

Nonetheless, the prohibition of Cannabis cultivation and the related research has created a large gap of knowledge on the genetics of the varieties and breeding for desired traits. Currently, a vast number of Cannabis strains exist, whose genotypic and metabolic backgrounds are largely unknown. The term "strain" refers to slight phenotypic differences and branding rather than distinct genotypic compositions. The above represent a bottleneck for Cannabis R\&D toward the development of hybrids exhibiting improved fiber, seed, bioactive molecule-producing capacities, and/or improved resistance to pests and pathogens. There are numerous examples of strains susceptible to pest and pathogen infections, leading to severe yield losses (McPartland et al., 2000; Clarke and Merlin, 2016).

All the above underline the necessity for the comprehensive genetic and metabolic mapping of the existent Cannabis strains in order to unravel the relationships between sub-species, the similarities among strains and phenotypes, and to discover single or sets of metabolites-biomarkers that could be further exploited in Cannabis breeding programs following biomarker-assisted approaches. Furthermore, the recently introduced legislation on the cultivation of industrial and medicinal Cannabis in many countries necessitates the use of certified genetic material from a scientific and industrial perspective.

Within this context, metabolomics represents a bioanalytical tool of high potential that could greatly assist and complement the currently applied breeding tools (Taylor et al., 2002; Fernie and Schauer, 2009; Herrmann and Schauer, 2013). This task could be further assisted by the employment of QQQ detectors, which exhibit superior capacities in metabolite quantification and identification (see $\$ 3$ ). Although a significant effort has been made toward the improvement of crops via breeding, its capacities in plants' selection for certain traits have been exploited only recently (Fernie and Schauer, 2009). Being the link between genotypes and phenotypes (Fiehn, 2002; Bino et al., 2004), metabolomics could greatly reduce the required time and the corresponding costs being an integrated component of plant-breeding programs (Figure 7). Focusing on Cannabis, its yield, potency, cannabinoid content, flowering, and resistance to pest and pathogen infections, are among the major traits of interest for breeding. In a recent metabolomics study (Mudge et al., 2018), it was shown that Cannabis domestication has resulted in an alteration of its metabolism involving the CBDA and THCA biosynthetic pathways. Additionally, the biomarker-assisted breeding could provide insights into attributes such as the "entourage effect," by breeding for traits related to cannabinoid and terpenoid contents (Grof, 2018). 


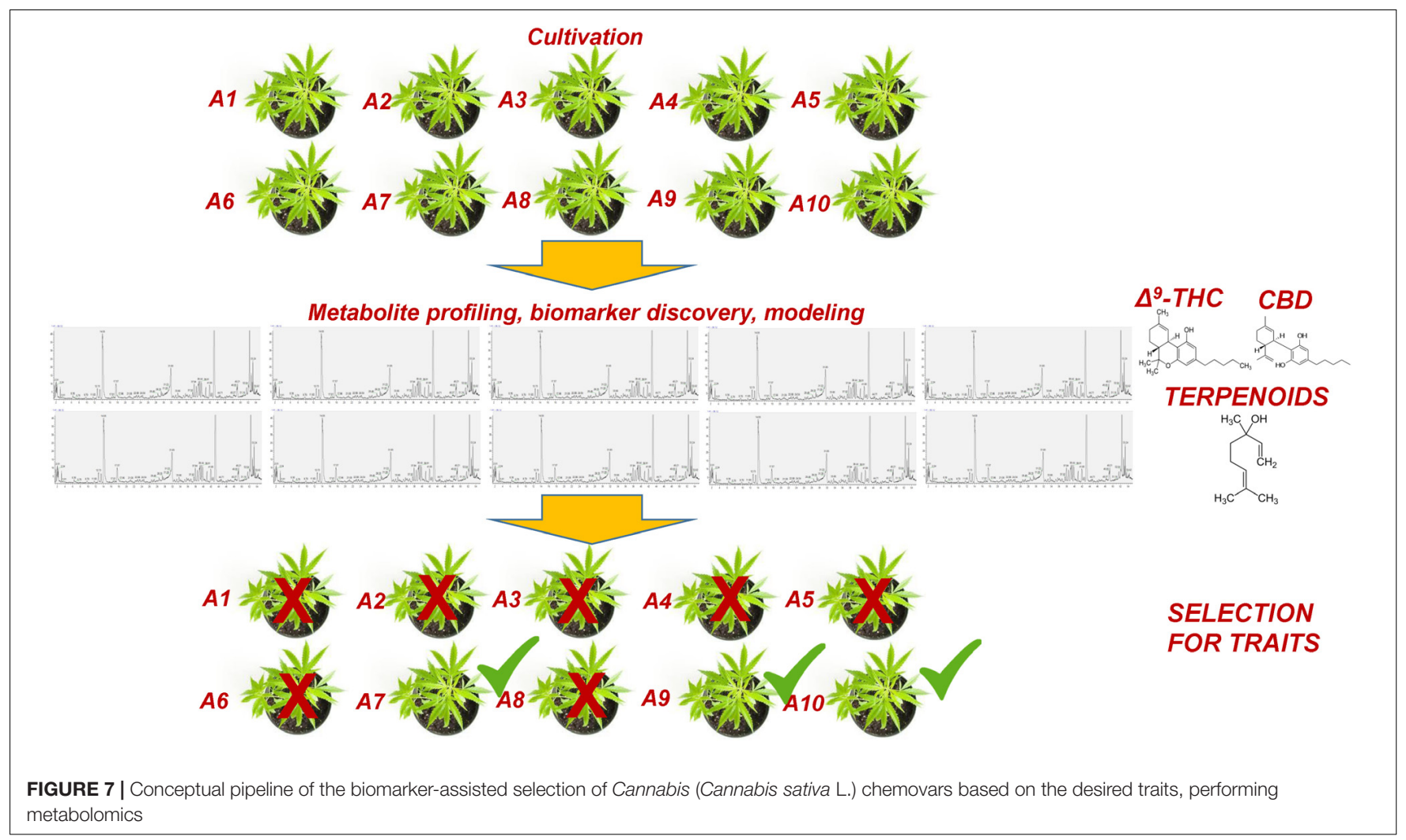

\section{CONCLUSION}

Cannabis is a species whose exploitation for applications in various fields has sparked great controversy. Nonetheless, there is a consensus that from a scientific perspective, the research on the plant could lead to significant advances for applications of extracts or individual metabolites in medicine, cosmetics, and the food industry. Currently, the recently introduced legislation on Cannabis in many countries around the world has enabled research on the plant and the vast array of its products. Cannabis matrices are extremely complex, requiring the implementation of advanced bioanalytical tools in order to gain meaningful insights into their bioactivity, medicinal properties, and risk assessment.

Based on its unique capacities and the developments in bioanalytics, is expected that metabolomics will greatly assist in impending Cannabis $\mathrm{R} \& \mathrm{D}$ contributing to the development of new, superior, efficient, and safe for the consumer, products. As a functional genomics tool, metabolomics could be ideally employed in the monitoring of cannabinoid and terpenoid profiles and their alterations in response to genotypic changes or agricultural treatments (e.g., fertilizers, bioelicitors, environmental conditions) and also in the biomarker-assisted selection of chemovars.

Additionally, the monitoring and comprehensive mapping of terpenoids could greatly assist the efforts toward understanding their synergy with cannabinoids. The modulation of the potency and medicinal properties of Cannabis extracts by their terpenoid content is largely unexplored. The acquisition of information on the effect of terpenoids on the medicinal properties of extracts could accelerate the discovery of novel drugs. The multistep engineering of the terpenoid biosynthetic pathway (Aharoni et al., 2005) and the generation of plants with knockout mutations via technologies such as the clustered regularly interspaced short palindromic repeats CRISPR (Ran et al., 2013) is feasible (Russo, 2018), and represents a great opportunity. Nonetheless, caution is required in applications of Cannabis for commercial purposes, which is expected to spark great controversy and face many regulatory hurdles.

Moreover, metabolomics is an invaluable tool that can be employed in the high-throughput chemotaxonomy or chemotyping of Cannabis strains into the corresponding chemovars based on their cannabinoid, terpenoid, and/or global metabolite profiles. Such classification is important not only for research but also for QC purposes. The correlation between Cannabis chemovars, their chemical composition, and their medicinal properties, is highly expected to accelerate drug discovery and development. From the current evidence, it is apparent that further experimentation is required for the development of Cannabis preparations or individual metabolites as drugs based on clinical trials (Soltesz et al., 2015), for which metabolomics should be an integrated component. Additionally, the employment and integration of advanced analyzers applying metabolomics is strongly expected to provide novel insights toward the understanding of the cannabinoid pharmacokinetics.

The comprehensive study of the effect of light on Cannabis metabolism and metabolite profiles could greatly contribute to the deconvolution of the underlying operating mechanisms that regulate the responses of plants to the various light regimes 
and their potency. This is expected to add a critical mass of information that could be exploited in the optimization of the light conditions in order to regulate its development toward the achievement of, among others, higher yields, improved and customized potency, and early flowering. Furthermore, the research on the scaling-up of the production of rare cannabinoids, cannabis-derived bioactives, or their synthetic analogs through the metabolic engineering of microorganisms, could be substantially accelerated through the application of metabolomics.

Nonetheless, there is a need for further optimization and validation of the available bioanalytical protocols that could be implemented in the routine analyses of Cannabis matrices for QC but also for R\&D purposes. The robustness of the GC-based platforms, which are the golden standard for metabolomics, faces the challenge of the heat-catalyzed conversions of several cannabinoids, which can be addressed by appropriate silylation protocols. Based on the limitations of the available instrumentation, there is not a single analyzer that could cover the remarkably diverse Cannabis metabolome. Additionally, the development of Cannabis-specific bioinformatics software and corresponding metabolite databases, would greatly contribute toward the development of metabolomics applicationsCanabinomics in Cannabis-related research disciplines. To the

\section{REFERENCES}

Aharoni, A., Jongsma, M. A., and Bouwmeester, H. J. (2005). Volatile science? Metabolic engineering of terpenoids in plants. Trends Plant Sci. 10, 594-602. doi: 10.1016/j.tplants.2005.10.005

Aliferis, K. A., and Chrysayi-Tokousbalides, M. (2011). Metabolomics in pesticide research and development: review and future perspectives. Metabolomics 7, 35-53. doi: 10.1007/s11306-010-0231-x

Aliferis, K. A., and Jabaji, S. (2011). Metabolomics-a robust bioanalytical approach for the discovery of the modes-of-action of pesticides: a review. Pestic. Biochem. Physiol. 100, 105-117. doi: 10.1016/j.pestbp.2011.03.004

Andre, C. M., Hausman, J.-F., and Guerriero, G. (2016). Cannabis sativa: the plant of the thousand and one molecules. Front. Plant Sci. 7:19. doi: 10.3389/fpls.2016. 00019

Appendino, G., Gibbons, S., Giana, A., Pagani, A., Grassi, G., Stavri, M., et al. (2008). Antibacterial Cannabinoids from Cannabis sativa: a structure-activity study. J. Nat. Prod. 71, 1427-1430. doi: 10.1021/np8002673

Atapattu, S. N., and Johnson, K. R. (2020). Pesticide analysis in cannabis products. J. Chromatogr. A 1612:460656. doi: 10.1016/j.chroma.2019.460656

Beale, D. J., Pinu, F. R., Kouremenos, K. A., Poojary, M. M., Narayana, V. K., Boughton, B. A., et al. (2018). Review of recent developments in GC-MS approaches to metabolomics-based research. Metabolomics 14:152. doi: 10. 1007/s11306-018-1449-2

Ben-Shabat, S., Fride, E., Sheskin, T., Tamiri, T., Rhee, M.-H., Vogel, Z., et al. (1998). An entourage effect: inactive endogenous fatty acid glycerol esters enhance 2-arachidonoyl-glycerol cannabinoid activity. Eur. J. Pharmacol. 353, 23-31. doi: 10.1016/S0014-2999(98)00392-6

Bino, R. J., Hall, R. D., Fiehn, O., Kopka, J., Saito, K., Draper, J., et al. (2004). Potential of metabolomics as a functional genomics tool. Trends Plant Sci. 9, 418-425. doi: 10.1016/j.tplants.2004.07.004

Blake, A., and Nahtigal, I. (2019). The evolving landscape of cannabis edibles. Curr. Opin. Food Sci. 28, 25-31. doi: 10.1016/j.cofs.2019.03.009

Bonvallot, N., David, A., Chalmel, F., Chevrier, C., Cordier, S., Cravedi, J.-P., et al. (2018). Metabolomics as a powerful tool to decipher the biological effects of environmental contaminants in humans. Curr. Opin. Food Sci. Toxicol. 8, 48-56. doi: 10.1016/j.cotox.2017.12.007 best of our knowledge, the current is the first overview of the application of metabolomics in Cannabis R\&D, which following the legalization of medicinal Cannabis, is highly foreseen to greatly assist Cannabis breeding and selection, being an unparalleled tool to link genotypes with phenotypes and potency, and predict traits based on modeling and machine learning.

\section{AUTHOR CONTRIBUTIONS}

KA and DB-P conceived the ideas and wrote the manuscript.

\section{FUNDING}

The work was supported by the Program of Graduate studies of the Agricultural University of Athens.

\section{ACKNOWLEDGMENTS}

We thank Ms. Hayley Clark for the editorial review of the manuscript.

Booth, J. K., Page, J. E., and Bohlmann, J. (2017). Terpene synthases from Cannabis sativa. PLoS One 12:e173911. doi: 10.1371/journal.pone.0173911

Bruni, N., Della Pepa, C., Oliaro-Bosso, S., Pessione, E., Gastaldi, D., and Dosio, F. (2018). Cannabinoid delivery systems for pain and inflammation treatment. Molecules 23:2478. doi: 10.3390/molecules23102478

Bundy, J. G., Davey, M. P., and Viant, M. R. (2009). Environmental metabolomics: a critical review and future perspectives. Metabolomics 5:3. doi: 10.1007/s11306008-0152-0

Burgie, E. S., Bussell, A. N., Walker, J. M., Dubiel, K., and Vierstra, R. D. (2014). Crystal structure of the photosensing module from a red/far-red light-absorbing plant phytochrome. $\iota$ Proc. Natl. Acad. Sci. U.S.A. 11, 10179-10184. doi: 10. 1073/pnas.1403096111

Caraceni, P., Borrelli, F., Giannone, F. A., and Izzo, A. A. (2014). "Potential therapeutic applications of cannabinoids in gastrointestinal and liver diseases: focus on $\Delta 9$-tetrahydrocannabinol pharmacology," in Cannabinoids ed. V. Di Marzo (Hoboken, NJ: John Wiley \& Sons, Ltd), 219-260. doi: 10.1002/ 9781118451281.ch7

Carvalho, Â., Hansen, E. H., Kayser, O., Carlsen, S., and Stehle, F. (2017). Designing microorganisms for heterologous biosynthesis of cannabinoids. FEMS Yeast Res. 17:fox037. doi: 10.1093/femsyr/fox037

Casida, J. E. (2009). Pest toxicology: the primary mechanisms of pesticide action. Chem. Res. Toxicol. 22, 609-619. doi: 10.1021/tx8004949

Casida, J. E. (2010). Curious about pesticide action. J. Agric. Food Chem. 59, 2762-2769. doi: 10.1021/jf102111s

Caspi, R., Billington, R., Ferrer, L., Foerster, H., Fulcher, C. A., Keseler, I. M., et al. (2015). The MetaCyc database of metabolic pathways and enzymes and the BioCyc collection of pathway/genome databases. Nucleic Acids Res. 44, D471-D480. doi: 10.1093/nar/gkm900

Castro-Puyana, M., and Herrero, M. (2013). Metabolomics approaches based on mass spectrometry for food safety, quality and traceability. Trends Anal. Chem. 52, 74-87. doi: 10.1016/j.trac.2013.05.016

Cevallos-Cevallos, J. M., Reyes-De-Corcuera, J. I., Etxeberria, E., Danyluk, M. D., and Rodrick, G. E. (2009). Metabolomic analysis in food science: a review. Trends Food Sci. Technol. 20, 557-566. doi: 10.1016/j.tifs.2009.07.002

Chandra, S., Lata, H., Khan, I. A., and Elsohly, M. A. (2017). "Cannabis sativa L.: botany and horticulture," in Cannabis sativa L. - Botany and Biotechnology, 
eds S. Chandra, H. Lata and M. A. Elsohly (Cham: Springer), 79-100. doi: 10.1007/978-3-319-54564-6_3

Chandra, S., Lata, H., Mehmedic, Z., Khan, I. A., and Elsohly, M. A. (2015). Light dependence of photosynthesis and water vapor exchange characteristics in different high $\triangle 9$-THC yielding varieties of Cannabis sativa L. J. Appl. Res. Med. Aromat. Plants 2, 39-47. doi: 10.1016/j.jarmap.2015.03.002

Charlebois, S., Somogyi, S., and Sterling, B. (2018). Cannabis-infused food and Canadian consumers' willingness to consider "recreational" cannabis as a food ingredient. Trends Food Sci. Technol. 74, 112-118. doi: 10.1016/j.tifs.2018. 02.009

Chen, T., Hao, J., He, J., Zhang, J., Li, Y., Liu, R., et al. (2013). Cannabisin B induces autophagic cell death by inhibiting the AKT/mTOR pathway and S phase cell cycle arrest in HepG2 cells. Food Chem. 138, 1034-1041. doi: 10.1016/ j.foodchem.2012.11.102

Chin, Y.-W., Balunas, M. J., Chai, H. B., and Kinghorn, A. D. (2006). Drug discovery from natural sources. AAPS J. 8, E239-E253. doi: 10.1007/ BF02854894

Choi, Y. H., Hazekamp, A., Peltenburg-Looman, A. M., Frédérich, M., Erkelens, C., Lefeber, A. W., et al. (2004). NMR assignments of the major cannabinoids and cannabiflavonoids isolated from flowers of Cannabis sativa. Phytochem. Anal. 15, 345-354. doi: 10.1002/pca.787

Citti, C., Palazzoli, F., Licata, M., Vilella, A., Leo, G., Zoli, M., et al. (2018). Untargeted rat brain metabolomics after oral administration of a single high dose of cannabidiol. J. Pharm. Biomed. Anal. 161, 1-11. doi: 10.1016/j.jpba. 2018.08.021

Clarke, R. C., and Merlin, M. D. (2013). Cannabis: Evolution and Ethnobotany. Berkeley, CA: University of California Press Ltd.

Clarke, R. C., and Merlin, M. D. (2016). Cannabis domestication, breeding history, present-day genetic diversity, and future prospects. Crit. Rev. Plant Sci. 35, 293-327. doi: 10.1080/07352689.2016.1267498

Cox, C. (2018). The Canadian Cannabis Act legalizes and regulates recreational Cannabis use in 2018. Health Policy 122, 205-209. doi: 10.1016/j.healthpol.2018. 01.009

Dando, I., Donadelli, M., Costanzo, C., Dalla Pozza, E., D’Alessandro, A., Zolla, L., et al. (2013). Cannabinoids inhibit energetic metabolism and induce AMPKdependent autophagy in pancreatic cancer cells. Cell Death Dis. 4:e664. doi: 10.1038/cddis.2013.151

Dayanandan, P., and Kaufman, P. B. (1976). Trichomes of Cannabis sativa L. (Cannabaceae). Am. J. Bot. 63, 578-591. doi: 10.1002/j.1537-2197.1976. tb11846.x

Dettmer, K., Aronov, P. A., and Hammock, B. D. (2007). Mass spectrometry-based metabolomics. Mass Spectrom. Rev. 26, 51-78. doi: 10.1002/mas.20108

Di Marzo, V. (2008). Targeting the endocannabinoid system: to enhance or reduce? Nat. Rev. Drug Discov. 7, 438-455. doi: 10.1038/nrd2553

Di Marzo, V., Bifulco, M., and De Petrocellis, L. (2004). The endocannabinoid system and its therapeutic exploitation. Nat. Rev. Drug Discov. 3, 771-784. doi: $10.1038 / \operatorname{nrd} 1495$

Dinis-Oliveira, R. J. (2016). Metabolomics of $\Delta 9$-tetrahydrocannabinol: implications in toxicity. Drug Metab. Rev. 48, 80-87. doi: 10.3109/03602532.2015. 1137307

Dittrich, P. S., and Manz, A. (2006). Lab-on-a-chip: microfluidics in drug discovery. Nat. Rev. Drug Discov. 5, 210-218. doi: 10.1038/nrd1985

Dudareva, N., Klempien, A., Muhlemann, J. K., and Kaplan, I. (2013). Biosynthesis, function and metabolic engineering of plant volatile organic compounds. New Phytol. 198, 16-32. doi: 10.1111/nph.12145

Dujourdy, L., and Besacier, F. (2017). A study of cannabis potency in France over a 25 years period (1992-2016). Forensic Sci. Int. 272, 72-80. doi: 10.1016/j. forsciint.2017.01.007

Elzinga, S., Fischedick, J., Podkolinski, R., and Raber, J. (2015). Cannabinoids and terpenes as chemotaxonomic markers in cannabis. Nat. Prod. Chem. Res. 3:4. doi: $10.4172 / 2329-6836.1000175$

Escrivá, Ú., Andrés-Costa, M. J., Andreu, V., and Picó, Y. (2017). Analysis of cannabinoids by liquid chromatography-mass spectrometry in milk, liver and hemp seed to ensure food safety. Food Chem. 228, 177-185. doi: 10.1016/j. foodchem.2017.01.128

Farag, S., and Kayser, O. (2015). "Cultivation and breeding of Cannabis sativa L. for preparation of standardized extracts for medicinal purposes," in Medicinal and Aromatic Plants of the World: Scientific, Production, Commercial and Utilization
Aspects, ed. Á. Máthé (Dordrecht: Springer), 165-186. doi: 10.1007/978-94017-9810-5_9

Fernie, A. R., and Schauer, N. (2009). Metabolomics-assisted breeding: a viable option for crop improvement? Trends Genet. 25, 39-48. doi: 10.1016/j.tig.2008. 10.010

Fiehn, O. (2002). Metabolomics-the link between genotypes and phenotypes," in Functional Genomics, ed. C. D. Town (Dordrecht: Springer), 155-171. doi: 10.1007/978-94-010-0448-0_11

Fischedick, J. T. (2017). Identification of terpenoid chemotypes among High (-)-trans- $\Delta^{9}$-Tetrahydrocannabinol-Producing Cannabis sativa L. Cultivars. Cannabis Cannabinoid Res. 2, 34-47. doi: 10.1089/can.2016.0040

Fischedick, J. T., Hazekamp, A., Erkelens, T., Choi, Y. H., and Verpoorte, R. (2010). Metabolic fingerprinting of Cannabis sativa L., cannabinoids and terpenoids for chemotaxonomic and drug standardization purposes. Phytochemistry 71 , 2058-2073. doi: 10.1016/j.phytochem.2010.10.001

Flores-Sanchez, I. J., Choi, Y. H., and Verpoorte, R. (2012). "Metabolite analysis of Cannabis sativa L. by NMR spectroscopy," in Functional Genomics, ed. C. D. Town (Dordrecht: Springer), 363-375. doi: 10.1007/978-1-61779-424-7_27

Fuhrer, T., and Zamboni, N. (2015). High-throughput discovery metabolomics. Curr. Opin. Biotechnol. 31, 73-78. doi: 10.1016/j.copbio.2014.08.006

Fukushima, A., Hikosaka, S., Kobayashi, M., Nishizawa, T., Saito, K., Goto, E., et al. (2018). A systems analysis with "simplified source-sink model" reveals metabolic reprogramming in a pair of source-to-sink organs during early fruit development in tomato by LED light treatments. Front. Plant Sci. 9:1439. doi: $10.3389 /$ fpls.2018.01439

Gagne, S. J., Stout, J. M., Liu, E., Boubakir, Z., Clark, S. M., and Page, J. E. (2012). Identification of olivetolic acid cyclase from Cannabis sativa reveals a unique catalytic route to plant polyketides. Proc. Natl. Acad. Sci. U.S.A. 109, 12811-12816. doi: 10.1073/pnas.1200330109

Gallily, R., Yekhtin, Z., and Hanuš, L. O. (2018). The anti-inflammatory properties of terpenoids from Cannabis. Cannabis Cannabinoid Res. 3, 282-290. doi: 10. 1089/can.2018.0014

Gallo-Molina, A. C., Castro-Vargas, H. I., Garzón-Méndez, W. F., Ramírez, J. A. M., Monroy, Z. J. R., King, J. W., et al. (2019). Extraction, isolation and purification of tetrahydrocannabinol from the Cannabis sativa L. plant using supercritical fluid extraction and solid phase extraction. J. Supercrit. Fluids 146, 208-216. doi: 10.1016/j.supflu.2019.01.020

Galvão, V. C., and Fankhauser, C. (2015). Sensing the light environment in plants: photoreceptors and early signaling steps. Curr. Opin. Neurobiol. 34, 46-53. doi: 10.1016/j.conb.2015.01.013

Gaoni, Y., and Mechoulam, R. (1964). Isolation, structure, and partial synthesis of an active constituent of hashish. J. Am. Chem. Soc. 86, 1646-1647. doi: 10.1021/ja01062a046

Garcia, P. C., Rivero, R. M., Ruiz, J. M., and Romero, L. (2003). The role of fungicides in the physiology of higher plants: implications for defense responses. Bot. Rev. 69:162.

Giese, M. W., Lewis, M. A., Giese, L., and Smith, K. M. (2015). Method for the analysis of cannabinoids and terpenes in Cannabis. J. AOAC Int. 98, 1503-1522. doi: 10.5740/jaoacint.15-116

Giordano, S., and Petrelli, A. (2008). From single-to multi-target drugs in cancer therapy: when aspecificity becomes an advantage. Curr. Med. Chem. 15, 422432. doi: $10.2174 / 092986708783503212$

Gorelick, J., and Bernstein, N. (2017). "Chemical and physical elicitation for enhanced Cannabinoid production in Cannabis," in Cannabis sativa L. - Botany and Biotechnology, eds S. Chandra, H. Lata and M. A. Elsohly (Cham: Springer), 439-456. doi: 10.1007/978-3-319-54564-6_21

Grof, C. P. (2018). Cannabis, from plant to pill. Br. J. Clin. Pharmacol. 84, 2463-2467. doi: 10.1111/bcp.13618

Gromski, P. S., Muhamadali, H., Ellis, D. I., Xu, Y., Correa, E., Turner, M. L., et al. (2015). A tutorial review: metabolomics and partial least squares-discriminant analysis-a marriage of convenience or a shotgun wedding. Anal. Chim. Acta 879, 10-23. doi: 10.1016/j.aca.2015.02.012

Gupta, S. D., and Agarwal, A. (2017). "Influence of LED Lighting on In vitro plant regeneration and associated cellular redox balance," in Light Emitting Diodes for Agriculture, ed. S. D. Gupta (Berlin: Springer), 273-303. doi: 10.1007/978-98110-5807-3_12

Guzman, M. (2003). Cannabinoids: potential anticancer agents. Nat. Rev. Cancer 3, 745-755. doi: $10.1038 / \mathrm{nrc1} 188$ 
Happyana, N., Agnolet, S., Muntendam, R., Van Dam, A., Schneider, B., and Kayser, O. (2013). Analysis of cannabinoids in laser-microdissected trichomes of medicinal Cannabis sativa using LCMS and cryogenic NMR. Phytochemistry 87, 51-59. doi: 10.1016/j.phytochem.2012.11.001

Happyana, N., and Kayser, O. (2013). Monitoring metabolites production and cannabinoids analysis in medicinal Cannabis trichomes during flowering period by 1 H NMR-based metabolomics. Planta Med. 79:SL44. doi: 10.1055/s-00331351870

Harvey, A. L. (2008). Natural products in drug discovery. Drug Discov. Today 13, 894-901. doi: 10.1016/j.drudis.2008.07.004

Hazekamp, A., and Fischedick, J. (2012). Cannabis-from cultivar to chemovar. Drug Test. Anal. 4, 660-667. doi: 10.1002/dta.407

Hazekamp, A., and Grotenhermen, F. (2010). Review on clinical studies with Cannabis and cannabinoids 2005-2009. Cannabinoids 5, 1-21.

Hazekamp, A., Tejkalová, K., and Papadimitriou, S. (2016). Cannabis: from cultivar to chemovar II-a metabolomics approach to Cannabis classification. Cannabis Cannabinoid Res. 1, 202-215. doi: 10.1089/can.2016.0017

Herrero, M., Simó, C., García-Cañas, V., Ibáñez, E., and Cifuentes, A. (2012). Foodomics: MS-based strategies in modern food science and nutrition. Mass Spectrom. Rev. 31, 49-69. doi: 10.1002/mas.20335

Herrmann, A., and Schauer, N. (2013). "Metabolomics-assisted plant breeding," in The Handbook of Plant Metabolomics, eds W. Weckwerth and G. Kahl (New York, NY: Wiley-VCH Verlag GmbH \& Co. KGaA), 245-254. doi: 10. 1002/9783527669882.ch13

Hillig, K. W. (2004). A chemotaxonomic analysis of terpenoid variation in Cannabis. Biochem. Syst. Ecol. 32, 875-891. doi: 10.1016/j.bse.2004.04.004

Hillig, K. W., and Mahlberg, P. G. (2004). A chemotaxonomic analysis of cannabinoid variation in Cannabis (Cannabaceae). Am. J. Bot. 91, 966-975. doi: 10.3732/ajb.91.6.966

Hu, Q., Noll, R. J., Li, H., Makarov, A., Hardman, M., and Graham Cooks, R. (2005). The Orbitrap: a new mass spectrometer. J. Mass Spectrom. 40, 430-443. doi: $10.1002 /$ jms.856

Ibáñez, C., Garcia-Canas, V., Valdés, A., and Simo, C. (2013). Novel MS-based approaches and applications in food metabolomics. Trends Anal. Chem. 52, 100-111. doi: 10.1016/j.trac.2013.06.015

Jain, R., and Singh, R. (2016). Microextraction techniques for analysis of cannabinoids. Trends Anal. Chem. 80, 156-166. doi: 10.1016/j.trac.2016.03.012

Kami, C., Lorrain, S., Hornitschek, P., and Fankhauser, C. (2010). Light-regulated plant growth and development. Curr. Top. Dev. Biol. Plant Dev. 91, 29-66. doi: 10.1016/S0070-2153(10)91002-8

Karp, P. D., Paley, S. M., Krummenacker, M., Latendresse, M., Dale, J. M., Lee, T. J., et al. (2009). Pathway Tools version 13.0: integrated software for pathway/genome informatics and systems biology. Brief. Bioinform. 11, 40-79. doi: 10.1093/bib/bbp043

Kim, E. S., and Mahlberg, P. G. (1991). Secretory cavity development in glandular trichomes of Cannabis sativa L. (Cannabaceae). Am. J. Bot. 78, 220-229. doi: 10.1002/j.1537-2197.1991.tb15749.x

Krahmer, J., Ganpudi, A., Abbas, A., Romanowski, A., and Halliday, K. J. (2018). Phytochrome, carbon sensing, metabolism, and plant growth plasticity. Plant Physiol. 176, 1039-1048. doi: 10.1104/pp.17.01437

Kusari, P., Kusari, S., Spiteller, M., and Kayser, O. (2013). Endophytic fungi harbored in Cannabis sativa L.: diversity and potential as biocontrol agents against host plant-specific phytopathogens. Fungal Divers. 60, 137-151. doi: 10.1007/s13225-012-0216-3

Lefsrud, M., Eichhorn Bilodeau, S., Wu, B. S., Rufyikiri, A. S., and MacPherson, S. (2019). An update on plant photobiology and implications for Cannabis production. Front. Plant Sci. 10:296. doi: 10.3389/fpls.2019.00296

Leghissa, A., Hildenbrand, Z. L., Foss, F. W., and Schug, K. A. (2018a). Determination of cannabinoids from a surrogate hops matrix using multiple reaction monitoring gas chromatography with triple quadrupole mass spectrometry. J. Sep. Sci. 41, 459-468. doi: 10.1002/jssc. 201700946

Leghissa, A., Hildenbrand, Z. L., and Schug, K. A. (2018b). A review of methods for the chemical characterization of Cannabis natural products. J. Sep. Sci. 41, 398-415. doi: 10.1002/jssc.201701003

Lewis, M. A., Russo, E. B., and Smith, K. M. (2018). Pharmacological foundations of cannabis chemovars. Planta Med. 84, 225-233. doi: 10.1055/s-0043- 122240

Liu, L., Redden, H., and Alper, H. S. (2013). Frontiers of yeast metabolic engineering: diversifying beyond ethanol and Saccharomyces. Curr. Opin. Biotechnol. 24, 1023-1030. doi: 10.1016/j.copbio.2013.03.005
Luo, X., Reiter, M. A., d'Espaux, L., Wong, J., Denby, C. M., Lechner, A., et al. (2019). Complete biosynthesis of cannabinoids and their unnatural analogues in yeast. Nature 567, 123-126. doi: 10.1038/s41586-019-0978-9

Lydon, J., and Duke, S. O. (1989). Pesticide effects on secondary metabolism of higher plants. Pestic. Sci. 25, 361-373. doi: 10.1002/ps.2780250406

Lydon, J., Teramura, A. H., and Coffman, C. B. (1987). UV-B radiation effects on photosynthesis, growth and cannabinoid production of two Cannabis sativa chemotypes. Photochem. Photobiol. 46, 201-206. doi: 10.1111/j.1751-1097.1987. tb04757.x

Madsen, R., Lundstedt, T., and Trygg, J. (2010). Chemometrics in metabolomics-a review in human disease diagnosis. Anal. Chim. Acta 659, 23-33. doi: 10.1016/ j.aca.2009.11.042

Magagnini, G., Grassi, G., and Kotiranta, S. (2018). The Effect of Light Spectrum on the Morphology and Cannabinoid Content of Cannabis sativa L. Med. Cannabis Cannabinoids 1, 19-27. doi: 10.1159/000489030

Malyshevskaya, O., Aritake, K., Kaushik, M. K., Uchiyama, N., Cherasse, Y., Kikura-Hanajiri, R., et al. (2017). Natural ( $\Delta$ 9-THC) and synthetic (JWH-018) cannabinoids induce seizures by acting through the cannabinoid CB 1 receptor. Sci. Rep. 7:10516. doi: 10.1038/s41598-017-10447-2

Mansouri, H., Asrar, Z., and Mehrabani, M. (2009a). Effects of gibberellic acid on primary terpenoids and $\Delta 9$-Tetrahydrocannabinol in Cannabis sativa at Flowering Stage. J. Integr. Plant Biol. 51, 553-561. doi: 10.1111/j.1744-7909. 2009.00833.x

Mansouri, H., Asrar, Z., and Szopa, J. (2009b). Effects of ABA on primary terpenoids and $\Delta^{9}$-tetrahydrocannabinol in Cannabis sativa $\mathrm{L}$. at flowering stage. Plant Growth Regul. 58, 269-277. doi: 10.1007/s10725-009-9375-y

Mansouri, H., Salari, F., Asrar, Z., and Nasibi, F. (2016). Effects of ethephon on terpenoids in Cannabis sativa L. in vegetative stage. J. Essent. Oil Bear. Plants 19, 94-102. doi: 10.1080/0972060X.2015.1004122

Markley, J. L., Brüschweiler, R., Edison, A. S., Eghbalnia, H. R., Powers, R., Raftery, D., et al. (2017). The future of NMR-based metabolomics. Curr. Opin. Biotechnol. 43, 34-40. doi: 10.1016/j.copbio.2016.08.001

Marks, M. D., Tian, L., Wenger, J. P., Omburo, S. N., Soto-Fuentes, W., He, J., et al. (2009). Identification of candidate genes affecting $\Delta 9$-tetrahydrocannabinol biosynthesis in Cannabis sativa. J. Exp. Bot. 60, 3715-3726. doi: 10.1093/jxb/ $\operatorname{erp} 210$

Mazur, A., Lichti, C. F., Prather, P. L., Zielinska, A. K., Bratton, S. M., GallusZawada, A., et al. (2009). Characterization of human hepatic and extrahepatic UDP-glucuronosyltransferase enzymes involved in the metabolism of classic cannabinoids. Drug Metab. Dispos. 37, 1496-1504. doi: 10.1124/dmd.109. 026898

McPartland, J. M. (1996a). A review of Cannabis diseases. J. Intl. Hemp Assoc. 3, 19-23.

McPartland, J. M. (1996b). Cannabis pests. J. Intl. Hemp Assoc. 3, 49-52.

McPartland, J. M., Clarke, R. C., and Watson, D. P. (2000). Hemp Diseases and Pests: Management and Biological Control: An Advanced Treatise. Trowbridge: CABI Publishing.

McPartland, J. M., and McKernan, K. J. (2017). "Contaminants of concern in Cannabis: microbes, heavy metals and pesticides," in Cannabis sativa L. - Botany and Biotechnology, eds S. Chandra, H. Lata and M. A. Elsohly (Cham: Springer), 457-474. doi: 10.1007/978-3-319-54564-6_22

Mechoulam, R., and Gaoni, Y. (1965). A total synthesis of dl- $\Delta 1$ tetrahydrocannabinol, the active constituent of hashish. J. Am. Chem. Soc. 87, 3273-3275. doi: 10.1021/ja01092a065

Mechoulam, R., and Hanuš, L. R. (2000). A historical overview of chemical research on cannabinoids. Chem. Phys. Lipids 108, 1-13. doi: 10.1016/S0009-3084(00) 00184-5

Mechoulam, R., and Parker, L. A. (2013). The endocannabinoid system and the brain. Annu. Rev. Psychol. 64, 21-47.

Mechoulam, R., Parker, L. A., and Gallily, R. (2002). Cannabidiol: an overview of some pharmacological aspects. J. Clin. Pharmacol. 42, 11S-19S. doi: 10.1002/j. 1552-4604.2002.tb05998.x

Meng, Q., Buchanan, B., Zuccolo, J., Poulin, M. M., Gabriele, J., and Baranowski, D. C. (2018). A reliable and validated LC-MS/MS method for the simultaneous quantification of 4 cannabinoids in 40 consumer products. PLoS One 13:e0196396. doi: 10.1371/journal.pone.0196396

Ming, R., Bendahmane, A., and Renner, S. S. (2011). Sex chromosomes in land plants. Annu. Rev. Plant Biol. 62, 485-514. doi: 10.1146/annurev-arplant042110-103914 
Mondello, L., Tranchida, P. Q., Dugo, P., and Dugo, G. (2008). Comprehensive two-dimensional gas chromatography-mass spectrometry: a review. Mass Spec. Rev. 27, 101-124. doi: 10.1002/mas.20158

Morales, P., Reggio, P. H., and Jagerovic, N. (2017). An overview on medicinal chemistry of synthetic and natural derivatives of cannabidiol. Front. Pharmacol. 8:422. doi: 10.3389/fphar.2017.00422

Morita, H., Wong, C. P., and Abe, I. (2019). How structural subtleties lead to molecular diversity for the type III polyketide synthases. J. Biol. Chem. 294, 15121-15136. doi: 10.1074/jbc.REV119.006129

Mudge, E., Murch, S., and Brown, P. (2016). Evaluating phytochemical variation in medical marihuana. Planta Med. 82, S1-S381. doi: 10.1055/s-0036- 1596181

Mudge, E., Murch, S., and Brown, P. (2018). Chemometric analysis of cannabinoids: chemotaxonomy and domestication syndrome. Sci. Rep. 8:13090. doi: 10.1038/s41598-018-31120-2

Mudge, E. M., Brown, P. N., and Murch, S. J. (2019). The Terroir of Cannabis: terpene metabolomics as a tool to understand Cannabis sativa selections. Planta Med. 85, 781-796. doi: 10.1055/a-0915-2550

Nagana Gowda, G., and Raftery, D. (2016). Recent advances in NMR-based metabolomics. Anal. Chem. 89, 490-510. doi: 10.1021/acs.analchem.6b04420

Nagegowda, D. A. (2010). Plant volatile terpenoid metabolism: biosynthetic genes, transcriptional regulation and subcellular compartmentation. FEBS Lett. 584, 2965-2973. doi: 10.1016/j.febslet.2010.05.045

Nielsen, J., Larsson, C., van Maris, A., and Pronk, J. (2013). Metabolic engineering of yeast for production of fuels and chemicals. Curr. Opin. Biotechnol. 24, 398-404. doi: 10.1016/j.copbio.2013.03.023

Pacher, P., Batkai, S., and Kunos, G. (2005). "Cardiovascular pharmacology of cannabinoids," in Cannabinoids, ed. E. Perwee (Berlin: Springer-Verlag), 599625. doi: 10.1007/3-540-26573-2_20

Pacula, R. L., and Smart, R. (2017). Medical Marijuana and Marijuana Legalization. Ann. Rev. Clin. Psychol. 13, 397-419. doi: 10.1146/annurev-clinpsy-032816045128

Peč, J., Flores-Sanchez, I. J., Choi, Y. H., and Verpoorte, R. (2010). Metabolic analysis of elicited cell suspension cultures of Cannabis sativa L. by $1 \mathrm{H}-$ NMR spectroscopy. Biotechnol. Lett. 32, 935-941. doi: 10.1007/s10529-0100225-9

Pellati, F., Brighenti, V., Sperlea, J., Marchetti, L., Bertelli, D., and Benvenuti, S. (2018). New methods for the comprehensive analysis of bioactive compounds in Cannabis sativa L. (hemp). Molecules 23:E2639. doi: 10.3390/ molecules23102639

Pertwee, R. G. (2005). "Pharmacological actions of cannabinoids," in Cannabinoids, ed. E. Perwee (Berlin: Springer-Verlag), 1-51. doi: 10.1007/3-540-26573-2_1

Peschel, W., and Politi, M. (2015). 1H NMR and HPLC/DAD for Cannabis sativa L. chemotype distinction, extract profiling and specification. Talanta 140, 150-165. doi: 10.1016/j.talanta.2015.02.040

Petit, A.-N., Fontaine, F., Vatsa, P., Clément, C., and Vaillant-Gaveau, N. (2012). Fungicide impacts on photosynthesis in crop plants. Photosynth. Res. 111: 315-326. doi: 10.1007/s11120-012-9719-8

Pichersky, E., Noel, J. P., and Dudareva, N. (2006). Biosynthesis of Plant Volatiles: nature's Diversity and Ingenuity. Science 311, 808-811. doi: 10.1126/science. 1118510

Politi, M., Peschel, W., Wilson, N., Zloh, M., Prieto, J. M., and Heinrich, M. (2008). Direct NMR analysis of cannabis water extracts and tinctures and semiquantitative data on $\Delta^{9}$-THC and $\Delta^{9}$-THC-acid. Phytochemistry 69, 562-570. doi: $10.1016 /$ j.phytochem.2007.07.018

Porras-Alfaro, A., and Bayman, P. (2011). Hidden fungi, emergent properties: endophytes and microbiomes. Annu. Rev. Phytopathol. 49, 291-315. doi: 10. 1146/annurev-phyto-080508-081831

Raghavendra, A. S., Gonugunta, V. K., Christmann, A., and Grill, E. (2010). ABA perception and signalling. Trends Plant Sci. 15, 395-401. doi: 10.1016/j.tplants. 2010.04.006

Rahn, B., Pearson, B. J., Trigiano, R. N., and Gray, D. J. (2016). The derivation of modern cannabis varieties. Crit. Rev. Plant Sci. 35, 328-348. doi: 10.1080/ 07352689.2016.1273626

Ramautar, R., Somsen, G. W., and De Jong, G. J. (2009). CE-MS in metabolomics. Electrophoresis 30, 276-291. doi: 10.1002/elps.200800512

Ramirez, C. L., Fanovich, M. A., and Churio, M. S. (2019). Cannabinoids: extraction methods, analysis, and physicochemical characterization. Stud. Nat. Prod. Chem. 61, 143-173. doi: 10.1016/B978-0-444-64183-0.00004-X
Ran, F. A., Hsu, P. D., Wright, J., Agarwala, V., Scott, D. A., and Zhang, F. (2013). Genome engineering using the CRISPR-Cas9 system. Nat. Protoc. 8, 2281-2308. doi: 10.1038/nprot.2013.143

Rosenberg, E. C., Patra, P. H., and Whalley, B. J. (2017). Therapeutic effects of cannabinoids in animal models of seizures, epilepsy, epileptogenesis, and epilepsy-related neuroprotection. Epilepsy Behav. 70, 319-327. doi: 10.1016/j. yebeh.2016.11.006

Rovetto, L. J., and Aieta, N. V. (2017). Supercritical carbon dioxide extraction of cannabinoids from Cannabis sativa L. J. Supercr. Fluids 129, 16-27. doi: 10.1016/j.supflu.2017.03.014

Russo, E. B. (2011). Taming THC: potential cannabis synergy and phytocannabinoid-terpenoid entourage effects. Br. J. Pharmacol. 163, 1344-1364. doi: 10.1111/j.1476-5381.2011.01238.x

Russo, E. B. (2018). The case for the entourage effect and conventional breeding of clinical Cannabis: No “Strain,” No Gain. Front. Plant Sci. 9:1969. doi: 10.3389/ fpls.2018.01969

Russo, E. B., Jiang, H.-E., Li, X., Sutton, A., Carboni, A., Del Bianco, F., et al. (2008). Phytochemical and genetic analyses of ancient cannabis from Central Asia. J. Exp. Bot. 59, 4171-4182. doi: 10.1093/jxb/ern260

Russo, E. B., and Marcu, J. (2017). Cannabis pharmacology: the usual suspects and a few promising leads. Adv. Pharmacol. 80, 67-134. doi: 10.1016/bs.apha.2017. 03.004

Sandler, L. N., Beckerman, J. L., Whitford, F., and Gibson, K. A. (2019). Cannabis as conundrum. Crop Protect. 117, 37-44. doi: 10.1016/j.cropro.2018.11.003

Scott, M., Rani, M., Samsatly, J., Charron, J.-B., and Jabaji, S. (2018). Endophytes of industrial hemp (Cannabis sativa L.) cultivars: identification of culturable bacteria and fungi in leaves, petioles, and seeds. Can. J. Microbiol. 64, 664-680. doi: 10.1139/cjm-2018-0108

Small, E., and Cronquist, A. (1976). A practical and natural taxonomy for Cannabis. Taxon 405-435. doi: 10.2307/1220524

Smolinska, A., Blanchet, L., Buydens, L. M., and Wijmenga, S. S. (2012). NMR and pattern recognition methods in metabolomics: from data acquisition to biomarker discovery: a review. Anal. Chim. Acta 750, 82-97. doi: 10.1016/j.aca. 2012.05.049

Soltesz, I., Alger, B. E., Kano, M., Lee, S.-H., Lovinger, D. M., Ohno-Shosaku, T., et al. (2015). Weeding out bad waves: towards selective cannabinoid circuit control in epilepsy. Nat. Rev. Neurosci. 16, 264-277. doi: 10.1038/nrn 3937

Stout, J. M., Boubakir, Z., Ambrose, S. J., Purves, R. W., and Page, J. E. (2012). The hexanoyl-CoA precursor for cannabinoid biosynthesis is formed by an acyl-activating enzyme in Cannabis sativa trichomes. Plant J. 71, 353-365. doi: 10.1111/j.1365-313X.2012.04949.x

Stutte, G. W. (2015). Commercial transition to LEDs: a pathway to high-value products. HortScience 50, 1297-1300. doi: 10.21273/HORTSCI.50.9.1297

Sumner, L. W., Lei, Z., Nikolau, B. J., and Saito, K. (2015). Modern plant metabolomics: advanced natural product gene discoveries, improved technologies, and future prospects. Nat. Prod. Rep. 32, 212-229. doi: 10.1039/ C4NP00072B

Taura, F., Tanaka, S., Taguchi, C., Fukamizu, T., Tanaka, H., Shoyama, Y., et al. (2009). Characterization of olivetol synthase, a polyketide synthase putatively involved in cannabinoid biosynthetic pathway. FEBS Lett. 583, 2061-2066. doi: 10.1016/j.febslet.2009.05.024

Taylor, J., King, R. D., Altmann, T., and Fiehn, O. (2002). Application of metabolomics to plant genotype discrimination using statistics and machine learning. Bioinformatics 18, S241-S248. doi: 10.1093/bioinformatics/18.suppl_ 2.S241

Tholl, D. (2006). Terpene synthases and the regulation, diversity and biological roles of terpene metabolism. Curr. Opin. Plant Biol. 9, 297-304. doi: 10.1016/j. pbi.2006.03.014

Van Bakel, H., Stout, J. M., Cote, A. G., Tallon, C. M., Sharpe, A. G., Hughes, T. R., et al. (2011). The draft genome and transcriptome of Cannabis sativa. Genome Biol. 12:R102. doi: 10.1186/gb-2011-12-10-r102

Velasco, G., Sánchez, C., and Guzmán, M. (2012). Towards the use of cannabinoids as antitumour agents. Nat. Rev. Cancer 12, 436-444. doi: 10.1038/nrc3247

Viant, M. R., Ebbels, T. M., Beger, R. D., Ekman, D. R., Epps, D. J., Kamp, H., et al. (2019). Use cases, best practice and reporting standards for metabolomics in regulatory toxicology. Nat. Commun. 10:3041. doi: 10.1038/s41467-01910900-y 
Viudez-Martínez, A., García-Gutiérrez, M. S., Medrano-Relinque, J., Navarrón, C. M., Navarrete, F., and Manzanares, J. (2018). Cannabidiol does not display drug abuse potential in mice behavior. Acta Pharmacol. Sin. 40, 358-364 doi: 10.1038/s41401-018-0032-8

Wang, X., Harrington, P. D. B., and Baugh, S. F. (2018). Effect of preprocessing high-resolution mass spectra on the pattern recognition of Cannabis, hemp, and liquor. Talanta 180, 229-238. doi: 10.1016/j.talanta.2017.12.032

Wishart, D. S. (2008). Metabolomics: applications to food science and nutrition research. Trends Food Sci. Technol. 19, 482-493. doi: 10.1016/j.tifs.2008. 03.003

Wishart, D. S. (2016). Emerging applications of metabolomics in drug discovery and precision medicine. Nat. Rev. Drug Discov. 15, 473-484. doi: 10.1038/nrd. 2016.32

Yang, X., Matsui, T., Kodama, T., Mori, T., Zhou, X., Taura, F., et al. (2016). Structural basis for olivetolic acid formation by a polyketide cyclase from Cannabis sativa. FEBS J. 283, 1088-1106. doi: 10.1111/febs. 13654

Yang, X., Xu, H., Shao, L., Li, T., Wang, Y., and Wang, R. (2018). Response of photosynthetic capacity of tomato leaves to different LED light wavelength. Environ. Exp. Bot. 150, 161-171. doi: 10.1016/j.envexpbot.2018. 03.013
Zager, J. J., Lange, I., Srividya, N., Smith, A., and Lange, B. M. (2019). Gene networks underlying cannabinoid and terpenoid accumulation in Cannabis. Plant Physiol. 180, 1877-1897. doi: 10.1104/pp.18.01506

Zimmermann, G. R., Lehar, J., and Keith, C. T. (2007). Multi-target therapeutics: when the whole is greater than the sum of the parts. Drug Discov. Today 12, 34-42. doi: 10.1016/j.drudis.2006.11.008

Conflict of Interest: The authors declare that the research was conducted in the absence of any commercial or financial relationships that could be construed as a potential conflict of interest.

The handling Editor declared a shared affiliation, though no other collaboration with one of the authors KA.

Copyright (C) 2020 Aliferis and Bernard-Perron. This is an open-access article distributed under the terms of the Creative Commons Attribution License (CC BY). The use, distribution or reproduction in other forums is permitted, provided the original author(s) and the copyright owner(s) are credited and that the original publication in this journal is cited, in accordance with accepted academic practice. No use, distribution or reproduction is permitted which does not comply with these terms. 